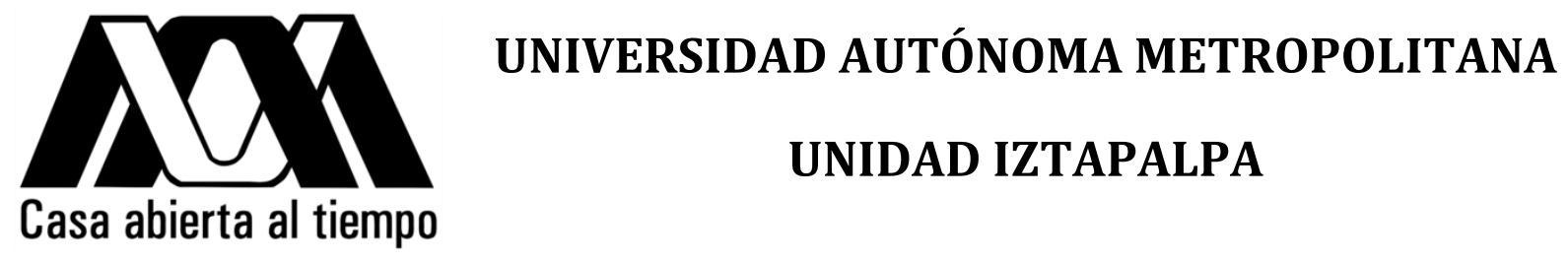

División de Ciencias Biológicas y de la Salud

Posgrado en Biología Experimental

\title{
ANÁLISIS DE LAS VÍAS INICIADORAS DE APOPTOSIS EN TIMOCITOS DE RATAS DESNUTRIDAS
}

TESIS

QUE PARA OBTENER EL GRADO DE MAESTRA EN BIOLOGÍA EXPERIMENTAL

PRESENTA

Donají López Torres

Directora de tesis:

Dra. Edith Cortés Barberena

Asesores:

Dra. Rocío Ortiz Muñiz

Dra. Sara Frías Vázquez

Dr. Humberto González Márquez

México D. F., a 15 de febrero de 2012. 


\section{AGRADECIMIENTOS INSTITUCIONALES}

El Programa de Maestría en Biología Experimental de la Universidad Autónoma Metropolitana pertenece al Programa Nacional de Posgrados de Excelencia del CONACyT (PNPC) registro 001481 y cuenta con apoyo del mismo Consejo, clave DAFCYT-2003IMPTNNN0020.

El presente trabajo se realizó en el laboratorio de Biología Celular y Citometría de Flujo, perteneciente al Departamento de Ciencias de la Salud de la Universidad Autónoma Metropolitana-Iztapalapa.

Para la realización de este trabajo se recibió apoyo CONACYT, a través del programa "Análisis de micronúcleos en organismos desnutridos", con clave 50804. Con apoyo adicional a los investigadores en proceso de consolidación (acuerdo número 118848) y beca CONACYT para estudios de maestría (número 233533).

Se agradece el apoyo recibido por la MVZ Rocío González y a su equipo de trabajo, por las facilidades otorgadas en el Bioterio de la Universidad Autónoma Metropolitana-Iztapalapa. 


\section{JURADO}

Los miembros del jurado designado por la División de Ciencias Biológicas y de la Salud de la Universidad Autónoma Metropolitana-Iztapalapa, abajo firmantes, aprobaron la tesis titulada "Análisis de las vías iniciadoras en timocitos de ratas desnutridas" el día 15 de febrero de 2012.

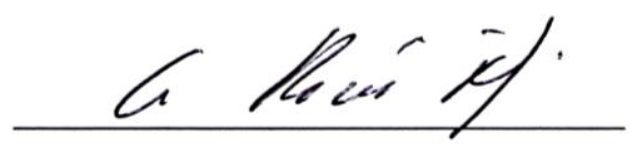

Presidenta: Dra. Rocío Ortiz Muñiz.

Universidad Autónoma Metropolitana - Unidad Iztapalapa.

Departamento de Ciencias de la Salud. arom@xanum.uam.mx

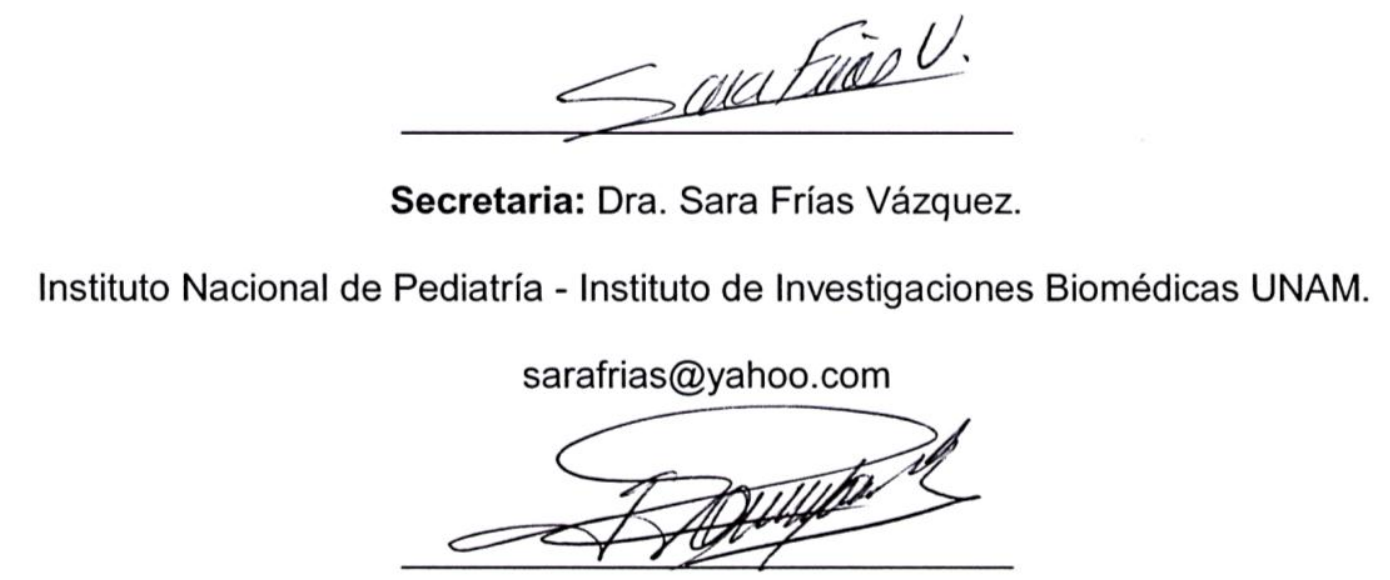

Vocal: Dr. Humberto González Márquez.

Universidad Autónoma Metropolitana - Unidad Iztapalapa.

Departamento de Ciencias de la Salud. hgm@xanum.uam.mx

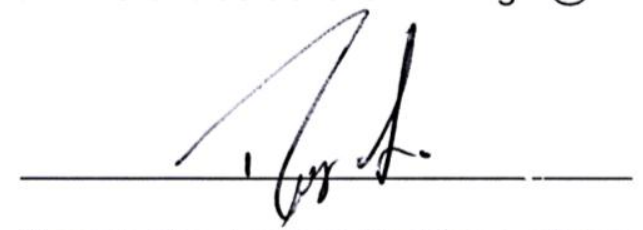

Vocal: Dra. Leonor Rodríguez Cruz.

Universidad Autónoma Metropolitana - Unidad Iztapalapa.

Departamento de Ciencias de la Salud. leor@xanum.uam.mx 


\section{COMITÉ TUTORAL}

\section{Directora:}

Dra. Edith Cortés Barberena.

Universidad Autónoma Metropolitana - Unidad Iztapalapa.

División de Ciencias Biológicas y de la Salud.

Departamento de Ciencias de la Salud.

cobe@xanum.uam.mx

\section{Asesora externa:}

Dra. Sara Frías Vázquez.

Instituto Nacional de Pediatría - Instituto de Investigaciones Biomédicas UNAM. Laboratorio de Citogenética.

sarafrias@yahoo.com

\section{Asesores internos:}

Dra. Rocío Ortiz Muñiz.

Universidad Autónoma Metropolitana - Unidad Iztapalapa.

División de Ciencias Biológicas y de la Salud.

Departamento de Ciencias de la Salud.

arom@xanum.uam.mx

Dr. Humberto González Márquez.

Universidad Autónoma Metropolitana - Unidad Iztapalapa.

División de Ciencias Biológicas y de la Salud.

Departamento de Ciencias de la Salud.

hgm@xanum.uam.mx 


\section{AGRADECIMIENTOS PERSONALES}

Indudablemente la realización de este trabajo involucró la colaboración de muchas personas, y sería poco fácil mencionar a todas, para aquellas que estuvieron involucradas directa e indirectamente: muchas gracias.

A la Dra. Rocío, por ser una gran mujer y un gran ejemplo en todo aspecto, que se caracteriza por un gran coraje, valentía y amor al prójimo.

A la Dra. Edith, por su paciencia, enseñanzas, alegrías y su invaluablemente apoyo en diversos aspectos de mi vida.

A la Dra. Leonor, por sus consejos, entusiasmo y su ejemplo. Es sin duda una mujer muy valiente y una gran madre.

A Elsa, Monserrat, Nancy y Claudia que me han brindado su amistad y ratos muy agradables. A Hilda †, quien por siempre vive en nuestros corazones, recordándola con mucho cariño y admiración.

A todos los profesores que contribuyeron a mi formación y siguen siendo la inspiración para muchos jóvenes ávidos de conocimientos.

A Justa y Gerardo, mis segundos padres, fuente de sabiduría y alegría. A Elvia y Silvestre, los tíos más amorosos.

A Alicia, por enseñarme que el fracaso no es mas que una forma de acercarse más al éxito, y que de nada sirve si no se aprende de él.

A Víctor y a Paulina por su ejemplo, disciplina, constancia y por ser los mejores hermanos que pude tener. A Josué por la alegría traída en su llegada.

A Miguel Ángel, por su apoyo y amor incondicional y a Ángel Uriel: la luz y la alegría de nuestras vidas. 


\section{RESUMEN.}

La desnutrición durante la infancia tiene un impacto importante en el crecimiento físico, mental y el desarrollo del individuo, es la causa más común de inmunodeficiencia a nivel mundial y de susceptibilidad a infecciones en humanos. Afecta principalmente al niño preescolar, debido a su rápido crecimiento los requerimientos nutrimentales son elevados, muy específicos y difíciles de satisfacer. El grado de desnutrición puede clasificarse por el porcentaje de déficit de peso en un individuo con relación a otro bien nutrido, en condiciones similares de edad y grupo étnico. Se conoce como desnutrición de primer grado o leve, a toda pérdida de peso entre el 10 y $25 \%$ del peso que el paciente debería tener para su edad; la desnutrición de segundo grado o moderada, se desarrolla cuando la pérdida de peso fluctúa entre el 25 y el $40 \%$ y finalmente desnutrición de tercer grado o grave, a la pérdida de peso del organismo más allá del $40 \%$. Los clasificados en el tercer grado de desnutrición son los que poseen un riesgo de mortalidad más elevado. El timo es altamente sensible a la condición nutricional y por ello se ha catalogado por varios autores como el "barómetro de la desnutrición". El microambiente generado por el timo también se ve afectado en la desnutrición, pues existen cambios morfológicos en las células epiteliales del timo, junto con una disminución en la producción de hormonas tímicas de las mismas, por lo que se observa que es un "órgano blanco" en la desnutrición. El presente trabajo tiene la finalidad de determinar la relación entre el incremento de la apoptosis en timocitos observada en ratas desnutridas cepa Wistar de 21 días de edad y las vías que la desencadenan, para poder establecer 
premisas que contribuyan a explicar el efecto de la desnutrición en el sistema inmunológico y su relación con la inmunodeficiencia. En este trabajo se analizó la apoptosis de los timocitos y sus subpoblaciones en ratas desnutridas y bien nutridas, mediante la presencia de caspasas en general y caspasas iniciadoras -8 y -9 , empleando la citometría de flujo. Los resultados muestran que la desnutrición afecta negativamente el desarrollo del timo y favorece al incremento de apoptosis temprana y tardía en los timocitos. Los timocitos CD4-CD8- y CD8+ son las subpoblaciones más afectadas por apoptosis, en desnutrición. Por otra parte, la desnutrición afecta la proporción de timocitos en las subpoblaciones. También se observó incremento de la proporción de timocitos positivos a caspasas -8 y -9 , por lo que ambas vías iniciadoras tienen un papel importante en el incremento de apoptosis en desnutrición; sin embargo, la proporción de timocitos positivos a caspasa-9 fue mayor que los positivos a caspasa-8, en CD4-CD8-, CD4+CD8+ y CD8+, lo que sugiere que la vía intrínseca posee un papel importante en el incremento de la apoptosis en dichas subpoblaciones. 


\section{ABSTRACT}

Malnutrition during childhood has a major impact on physical growth, mental and development of the individual and is the most common cause of global immunodeficiency and susceptibility to infections in humans. It affects mainly the preschool child due to its rapid growth, high nutrient requirements are very specific and difficult to satisfy. The degree of malnutrition may be classified by the percentage of underweight in an individual in relation to another well-nourished, under conditions similar age and ethnic group. Malnutrition is known as first-degree or mild, at all weight loss between 10 and $25 \%$ of the weight that the patient should be for their age, malnutrition or moderate second degree, occurs when the weight loss ranges from 25 to $40 \%$ and finally the third degree malnutrition or severe, the body weight loss beyond $40 \%$. Those classified in the third degree of malnutrition are those with a higher mortality risk. The thymus is highly sensitive to nutritional status and therefore has been classified by several authors as the "barometer of malnutrition". The microenvironment generated by the thymus is also affected in malnutrition, as there are morphological changes in thymic epithelial cells, along with a decrease in thymic hormone production of the same, so it is seen to be a "target organ" in malnutrition. The present study aims to determine the relationship between the increase in thymocyte apoptosis observed in malnourished Wistar rats 21 days of age and pathways that trigger in order to establish premises which contribute to explain the effect of malnutrition on the immune system and their relationship to immunodeficiency. In this study we analyzed the apoptosis of thymocytes and 
subpopulations, through the presence of caspases in general and initiator caspases 8 and -9 , using flow cytometry. The results show that malnutrition adversely affects thymic development and enhances the increase in early and late apoptosis in thymocytes. The CD4-CD8- and CD8+ thymocytes subpopulations are most affected by apoptosis, in malnutrition. Moreover, malnutrition affects the proportion of thymocytes in subpopulations. Also showed an increase in the proportion of positive thymocytes caspasas -8 and -9 , thus initiating both pathways have a role in increased apoptosis in malnutrition, but the proportion of thymocytes positive for caspase-9 was higher that caspase-8 positive in CD4-CD8-, CD4+CD8+ and CD8+, suggesting that the intrinsic pathway has a role in increased apoptosis in these subpopulations. 


\section{- ÍNDICE -}

$\begin{array}{ll}\text { ABREVIATURAS. } & 1\end{array}$

ÍNDICE DE ILUSTRACIONES, FIGURAS Y CUADRO. 4

1 INTRODUCCIÓN.

1.1 Desnutrición. $\quad 5$

2 ANTECEDENTES. $\quad 8$

$\begin{array}{lll}2.1 & \text { Infecciones asociadas a la desnutrición. } & 8\end{array}$

2.2 Efecto de la desnutrición en el timo. $\quad 9$

2.3 Importancia del timo. 12

2.4 Estudio de la desnutrición en modelos experimentales. 13

2.5 Características de la apoptosis. $\quad 14$

$\begin{array}{lll}2.6 & \text { Activación de caspasas. } & 15\end{array}$

$\begin{array}{llr}2.7 & \text { Apoptosis inducida por glucocorticoides. } & 18\end{array}$

2.8 Apoptosis y ciclo celular. 23

$3 \quad$ JUSTIFICACIÓN. $\quad 25$

4 HIPÓTESIS. $\quad 26$

$5 \quad$ OBJETIVO GENERAL. $\quad 27$

$\begin{array}{lll}5.1 & \text { Objetivos particulares. } & 27\end{array}$

6 MATERIAL Y MÉTODO. 28

6.1 Desnutrición experimental en ratas. 28

6.2 Obtención de timocitos. $\quad 29$

6.3 Determinación de la apoptosis en timocitos. 30

6.4 Estudio para la identificación de caspasas en timocitos. 33

6.5 Estudio de la apoptosis temprana y tardía en subpoblaciones de timocitos. 33 
6.6 Estudio de la apoptosis en las fases del ciclo celular, por cuantificación de ADN e identificación de caspasas.

6.7 Estudio de la apoptosis temprana en las subpoblaciones de timocitos, mediante la identificación de las caspasas iniciadoras de apoptosis -8 y -9.

6.8 Análisis estadístico.

7 RESULTADOS.

$\begin{array}{lll}7.1 & \text { Datos de las muestras estudiadas. } & 35\end{array}$

$\begin{array}{lll}7.2 & \text { Análisis de la apoptosis en timocitos. } & 37\end{array}$

7.3 Análisis de la apoptosis temprana y tardía en subpoblaciones de timocitos. 41

$\begin{array}{lll}7.4 & \text { Análisis de la apoptosis en las fases del ciclo celular. } & 48\end{array}$

7.5 Análisis de la apoptosis temprana en timocitos, mediante la identificación de las caspasas iniciadoras de apoptosis -8 y -9 .

7.6 Análisis de la apoptosis temprana en subpoblaciones de timocitos, mediante la presencia de las caspasas iniciadoras -8 y -9 .

8 DISCUSIÓN.

8.1 Datos de las muestras.

8.2 Apoptosis en timocitos.

8.3 Apoptosis temprana y tardía en subpoblaciones de timocitos.

$\begin{array}{lll}8.4 & \text { Apoptosis en las fases del ciclo celular. } & 67\end{array}$

$\begin{array}{lll}8.5 & \text { Apoptosis temprana en timocitos. } & 70\end{array}$

$\begin{array}{lll}\text { 8.6 Apoptosis temprana en las subpoblaciones de timocitos. } & 71\end{array}$

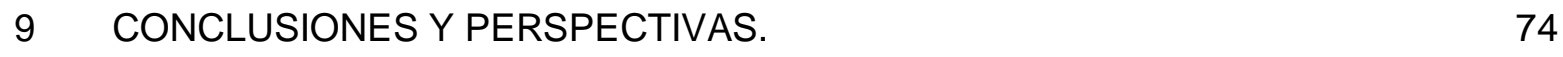

10 REFERENCIAS BIBLIOGRÁFICAS. 


\section{ABREVIATURAS.}

7-AAD 7-Amino Actinomicina D.

ADN Ácido desoxirribonucleico.

APAF-1 Factor activador-1 de proteasa apoptótica.

APC Aloficocianina.

ARN Ácido ribonucleico.

ARNasa Ribonucleasa.

BN Grupo de ratas bien nutridas.

BN DX Grupo de ratas bien nutridas tratadas con dexametasona.

C-BN Camada de crías bien nutridas.

CD95 Receptor perteneciente a la superfamilia de receptores de muerte.

CDK Cinasas dependientes de ciclinas.

CDK2 Cinasa dependiente de ciclina-2.

C-DN Camada de crías desnutridas.

ced-3 Gen que codifica para CED-3.

CED-3 Cell death abnormal-3, perteneciente al grupo de cisteín proteasas.

CRADD Proteína adaptadora que contiene un dominio de muerte.

DN Grupo de ratas desnutridas.

DN DX Grupo de ratas desnutridas tratadas con dexametasona.

E2F Familia de factores de transcripción con sitio de unión al ADN, involucrados en la expresión de genes relacionados a la progresión del ciclo celular.

FADD Proteína adaptadora asociada a Fas, con dominio de muerte. 
FAS Receptor de muerte celular, o Apo-1. Miembro de la familia del factor de necrosis tumoral.

FASL Ligando de FAS.

FITC Isotiocianato de fluoresceína.

FL1 Canal para la detección de la fluorescencia 1.

FL2 Canal para la detección de la fluorescencia 2.

FL2-A Canal para la detección de la fluorescencia para contenido de ADN.

FL2-W Canal para la detección del ancho de los pulsos de fluorescencia.

FL3 Canal para la detección de la fluorescencia 3.

FL4 Canal para la detección de la fluorescencia 4.

FLICA Inhibidor de caspasas conjugado a un fluorocromo.

FSC Parámetro para identificar la dispersión frontal de la luz a menos de 10 grados (Forward Scatter). Está relacionada con el tamaño celular.

G1 Fase G1. Las células poseen la misma cantidad de ADN que en la fase G0.

G2/M Fase G2/M. Las células ya han duplicado su ADN, se preparan a dividirse.

GC Glucocorticoides.

GCR Receptor de glucocorticoides.

GRE Elementos de respuesta a glucocorticoides.

ICE Enzima convertidora de interleucina 1 B, conocida como caspasa-1.

MHC I Complejo principal de histocompatibilidad tipo I. Presenta péptidos productos de la degradación proteosomal a los linfocitos T citotóxicos. 
MHC II Complejo principal de histocompatibilidad tipo II. Presenta moléculas derivadas de proteínas extracelulares a linfocitos T cooperadores.

PBS Solución amortiguadora salina de fosfatos.

PE R ficoeritrina.

PLC Fosfolipasa C.

RAIDD Proteína homóloga asociada a RIP con dominio de muerte.

RIP Proteína de interacción con el receptor de muerte.

ROS Especies reactivas de oxígeno.

S Fase S. Se caracteriza por la síntesis de ADN, previamente a la fase G2/M.

SSC Parámetro para identificar a la luz dispersada en ángulo recto (Side Scatter). Es proporcional a la complejidad de la estructura interna de la célula.

T CD4+ Linfocitos $T$ cooperadores. Establecen y maximizan las capacidades de defensa del sistema inmunológico.

T CD8+ Linfocitos T citotóxicos. Neutralizan células infectadas por microorganismos intracelulares, atacan a las células infectadas.

TCR Receptor de linfocitos $T$.

TCR-MHC Complejo de reconocimiento del receptor de células $\mathrm{T}$ y el complejo principal de histocompatibilidad.

TNF-R Receptor del factor de necrosis tumoral.

$\Delta \boldsymbol{\Psi} \quad$ Potencial de membrana mitocondrial. 


\section{ÍNDICE DE ILUSTRACIONES, FIGURAS Y CUADRO.}

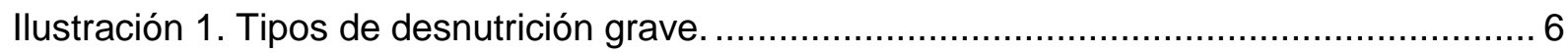

Ilustración 2. Localización anatómica y características histológicas del timo. ....................... 10

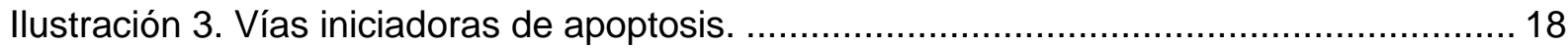

llustración 4. Mecanismo de inducción de apoptosis por GCs. ........................................... 22

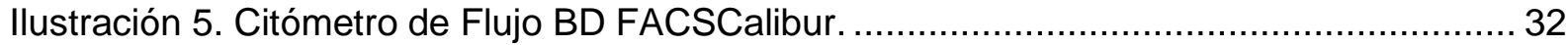

llustración 6. Gráficas de puntos para la identificación de timocitos..................................... 38

llustración 7. Gráfica para la identificación de subpoblaciones de timocitos.......................... 42

Ilustración 8. Identificación de timocitos en las fases del ciclo celular.................................48

Ilustración 9. Gráficas para la identificación de apoptosis temprana en timocitos. ................53

Ilustración 10. Análisis de apoptosis temprana en las subpoblaciones de timocitos..............57

Figura 1. Proporción de timocitos vivos, en apoptosis temprana, tardía y necrosis.............. 40

Figura 2. Proporción de timocitos en cada subpoblación en los grupos BN y DN. ............... 43

Figura 3. Análisis de apoptosis en timocitos CD4-CD8- para los grupos BN y DN. .............. 44

Figura 4. Análisis de apoptosis en timocitos CD4+CD8+ para los grupos BN y DN. ........... 45

Figura 5. Análisis de apoptosis en timocitos CD4+ para los grupos BN y DN. .................... 46

Figura 6. Análisis de apoptosis en timocitos CD8+ para los grupos BN y DN. …................ 47

Figura 7. Análisis de timocitos en cada fase del ciclo celular. ........................................... 50

Figura 8. Análisis de apoptosis de timocitos en las fases del ciclo celular............................. 52

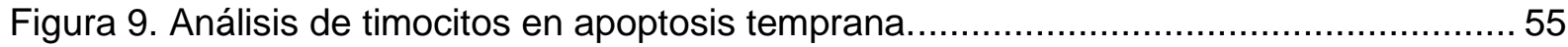

Figura 10. Apoptosis temprana analizada mediante la presencia de caspasa-8. ..................61 61

Figura 11. Apoptosis temprana analizada mediante la presencia de caspasa-9. …..............62 62

Figura 12. Timocitos en apoptosis temprana en cada subpoblación, para los grupos BN

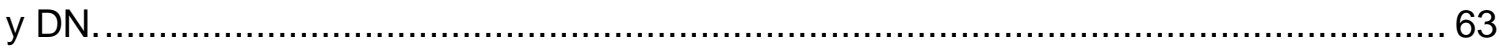

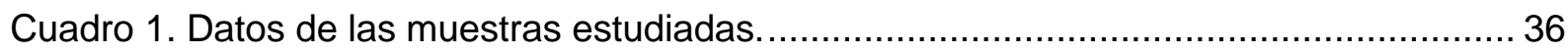




\section{INTRODUCCIÓN.}

\subsection{Desnutrición.}

La desnutrición se define como la asimilación deficiente de alimentos por el organismo que conduce a un estado patológico que presenta manifestaciones clínicas y gravedad variables (Gómez y cols., 1947). La desnutrición es la causa más común de inmunodeficiencia a nivel mundial y de susceptibilidad a infecciones en humanos (Chandra, 2002).

El grado de desnutrición puede clasificarse por el porcentaje de déficit de peso en un individuo con relación a otro bien nutrido, en condiciones similares de edad y grupo étnico. Se conoce como desnutrición de primer grado o leve, a toda pérdida entre el 10 y $25 \%$ de peso que el paciente debería tener para su edad; la desnutrición de segundo grado o moderada, se desarrolla cuando la pérdida de peso fluctúa entre el 25 y el $40 \%$ y finalmente desnutrición de tercer grado o grave, a la pérdida de peso del organismo más allá del 40 \% (Gómez, 1946).

La desnutrición grave se clasifica en tres tipos: kwashiorkor, marasmo y marasmokwashiorkor [llustración 1], de acuerdo con los siguientes criterios: A) el niño con desnutrición tipo kwashiorkor puede no presentar un peso inferior al $60 \%$ al esperado para la edad, dado que presenta edema y hepatomegalia, en ellos son frecuentes los cuadros de dermatosis; B) el niño con desnutrición tipo marasmo posee un peso menor o igual al $60 \%$ del peso esperado para la edad y no presenta edema, y C) el niño que posee menos del $60 \%$ del peso esperado, pero que presenta signos de 
edema, es clasificado como marasmo-kwashiorkor. El edema está casi siempre asociado con algún grado de hipoalbuminemia (Mukherjee, 1967; Waterlow, 1972).
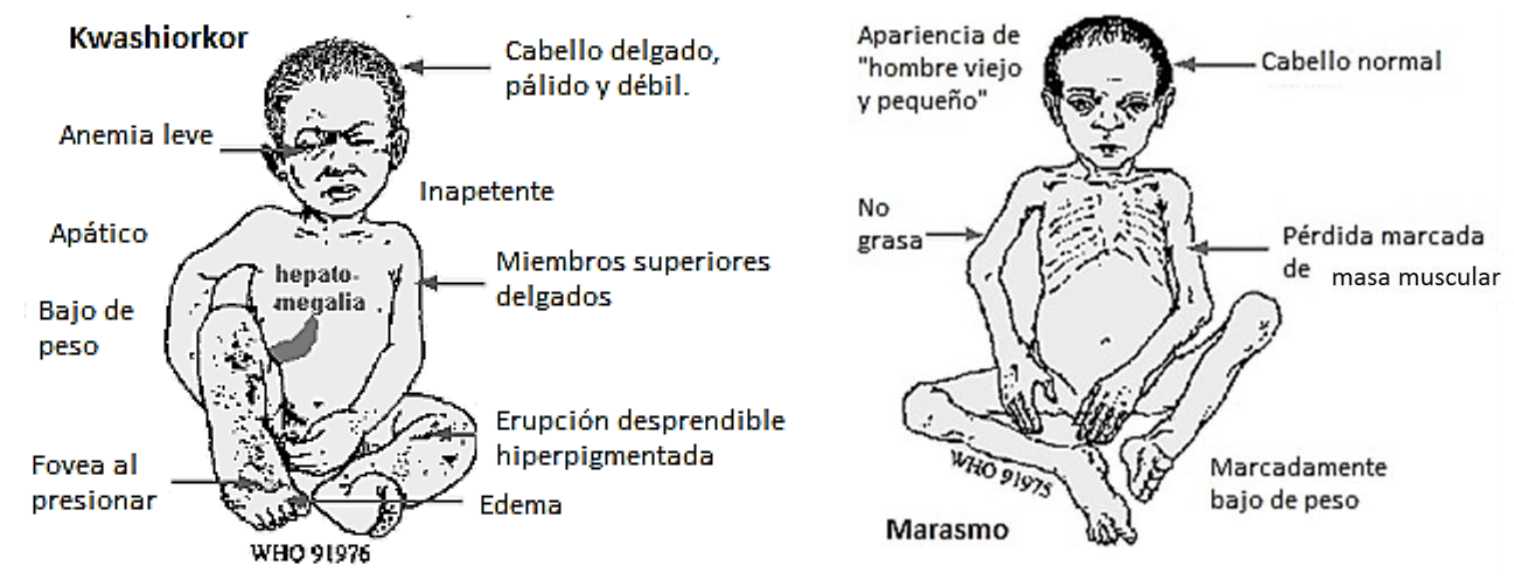

llustración 1. Tipos de desnutrición grave.

Izquierda: Características de la desnutrición tipo Kwashiorkor. Derecha: Desnutrición tipo marasmo. Figura modificada por el autor a partir de: WHO. ReadingsonDiarrhoea, 1992. Tomada de: Enlace Hispano Americano de Salud (www.ehas.org)

En los países en desarrollo una gran parte de los niños menores de 6 años ven restringidas sus posibilidades de crecimiento y desarrollo debido a problemas nutricionales. La desnutrición infantil produce graves consecuencias a nivel individual y social. Existe una relación estrecha entre el momento de desnutrirse con las etapas críticas del desarrollo cerebral. Junto con las alteraciones cerebrales se producen otras, destacándose déficit en el peso, talla y bajo nivel de inmunidad frente a las enfermedades infecciosas. La desnutrición afecta principalmente al niño preescolar (2 a 6 años), debido a su rápido crecimiento los requerimientos nutrimentales son elevados, muy específicos y difíciles de satisfacer. Por otra parte, los niños dependen 
de terceros para una alimentación correcta y muchas veces no cuentan con los recursos económicos suficientes o carecen de un nivel cultural y educacional adecuados para brindárselas (Pérez-Robles y cols., 1994).

A pesar de los avances científicos y médicos, las enfermedades infecciosas siguen siendo un reto para los sistemas de salud. Las enfermedades del rezago epidemiológico: diarreas, infecciones respiratorias y desnutrición, siguen provocando el $15 \%$ de los fallecimientos en menores de un año. Las infecciones respiratorias agudas, junto con otras enfermedades de la infancia, como las diarreicas y las deficiencias de la nutrición, son en México la principal causa de demanda de atención médica en los menores de cinco años. En la Encuesta Nacional de Salud y Nutrición de 2006 (ENSANUT 2006) se encontró que la prevalencia general de infecciones respiratorias agudas en los niños menores de 10 años fue de $42.7 \%$. Los resultados de la ENSANUT 2006 muestran que en el país 472890 (5\%) niños menores de cinco años tuvieron peso bajo; 1194805 (12.7\%), talla baja y alrededor de 153000 (1.6\%), presentaban marasmo (Olaiz-Fernández y cols., 2006). 


\section{ANTECEDENTES.}

\subsection{Infecciones asociadas a la desnutrición.}

La relación que existe entre la desnutrición, la supresión de la respuesta inmunológica y la infección es compleja, puesto que las infecciones por si mismas pueden contribuir a la desnutrición; por ejemplo, las infecciones gastrointestinales y parasitarias suelen provocar anemia y privación de nutrientes (Scrimshaw y cols., 1968). La estimulación de la respuesta inmunológica a causa de la infección incrementa la demanda de derivados metabólicos energéticos y sus sustratos asociados, lo que incrementa la desnutrición, siguiendo un círculo vicioso que se asocia al proceso de la infección (Bronte y Zanovello, 2005).

La desnutrición proteica grave en recién nacidos y niños preescolares provoca atrofia en el timo, asociado a la disminución celular y un mal desarrollo de los órganos linfoides periféricos (Savino, 2002). Esto inicia una cadena que provoca defectos inmunológicos caracterizados por leucopenia, disminuyendo la proporción de linfocitos T CD4+ y CD8+, e incrementando el número de células T doble negativas e inmaduras en la periferia (Schaible y Kaufmann, 2007). 


\subsection{Efecto de la desnutrición en el timo.}

El timo es un órgano linfoide primario bilobulado, formado por corteza y médula. Se localiza en la cavidad torácica [llustración 2]. Al timo llegan los precursores de los linfocitos $T$ (timocitos), procedentes del hígado en el periodo prenatal y posteriormente de la médula ósea, allí maduran hasta dar origen a linfocitos T. Los timocitos son seleccionados positiva y negativamente por las células epiteliales y macrófagos residentes del timo.

El timo es altamente sensible a la condición nutricional y por ello se ha catalogado por varios autores como el "barómetro de la desnutrición" (Prentice, 1999).

Al estudiar los timos post mortem de niños desnutridos se ha demostrado que la desnutrición se asocia con la atrofia del timo, así como con la disminución de linfocitos timo-dependientes en los ganglios linfáticos y el bazo (Purtilo y Connor, 1975).

La desnutrición afecta tanto a los elementos linfoides como epiteliales del timo. Al estudiar los timos de niños desnutridos, Lyra y colaboradores reportaron incremento de la matriz extracelular de la red intralobular. Esta matriz extracelular anormal contiene fibronectina, laminina y colágeno IV, y podría ser una causa en la que el contacto de los timocitos con la matriz extracelular anormal active y/o incremente la muerte celular programada (Lyra y cols., 1993). 

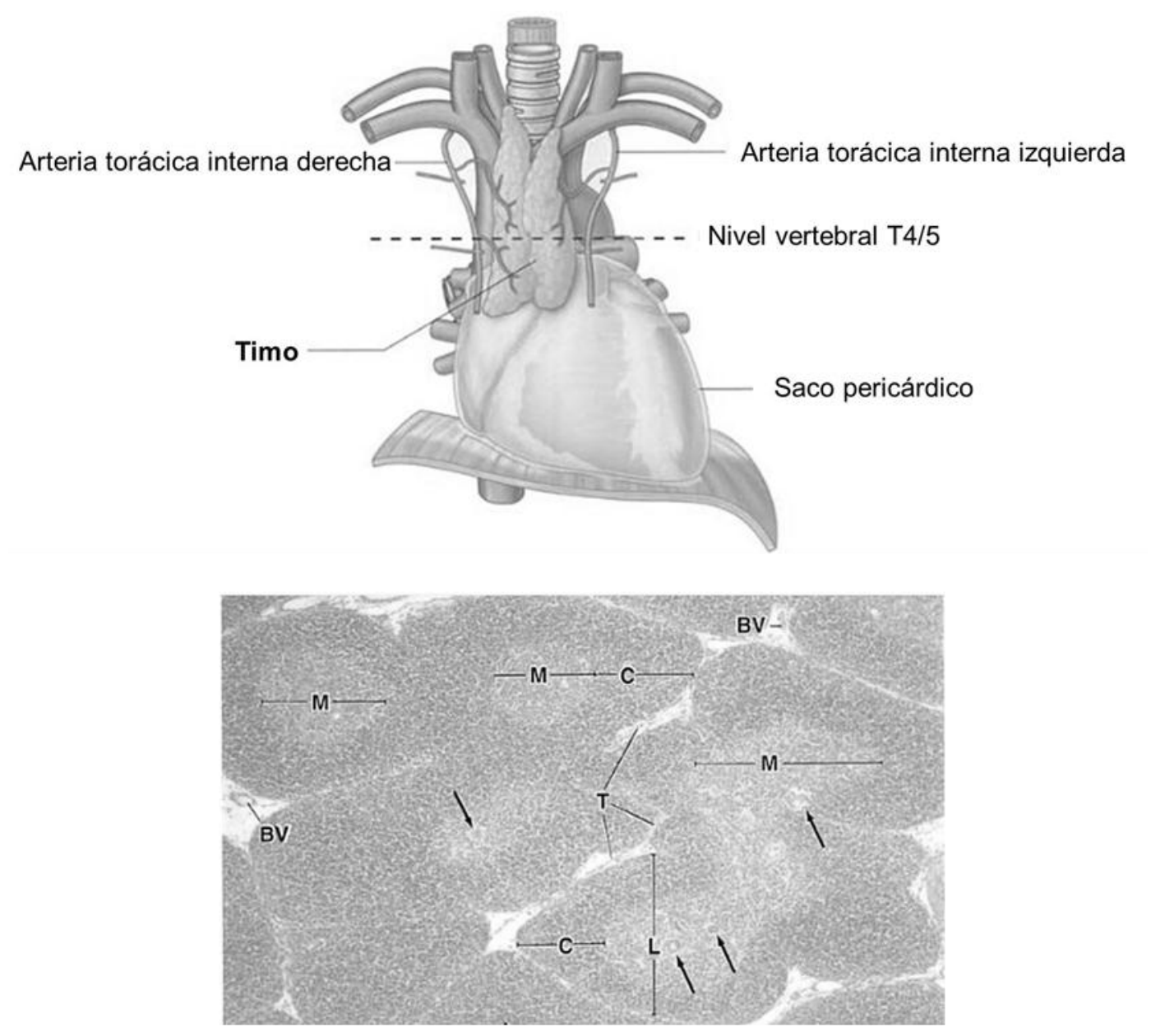

Ilustración 2. Localización anatómica y características histológicas del timo.

Superior: Localización anatómica del timo. Ilustración tomada de: Gray anatomía para estudiantes. Richard L. Drake, Wayne Vogl, Adam W. M. Mitchell. Elsevier España, 2005página 183.Inferior: Corte histológico del timo (4 X), los lobulillos (L) están formados por una corteza $(\mathrm{C})$ basófila muy teñida y una médula $(\mathrm{M})$ más pálida. La corteza contiene una cantidad abundante de linfocitos, mientras que en la médula la cantidad de linfocitos es menor, y en consecuencia, se hallan más separados. Foto tomada de: Histología: Texto y Atlas. Michael H. Ross, Wojciech Pawlina. Ed. Médica Panamericana 5ª Edición, página 479. 
El microambiente generado por el timo también se ve afectado en la desnutrición, pues existen cambios morfológicos en las células epiteliales del timo, junto con una disminución en su producción de hormonas tímicas, por lo que se observa que es un "órgano blanco" en la desnutrición (Savino, 2002).

En 1993 Barone y colaboradores caracterizaron los cambios en las subpoblaciones de linfocitos T durante la atrofia tímica inducida por desnutrición proteica en modelos murinos. Observaron una correlación directa entre los niveles de corticosterona sérica y la atrofia tímica. La corticosterona, en los niveles observados en ratones con deficiencia proteica, induce atrofia tímica en ratones normales (Barone y cols., 1993). Aunado a la baja actividad de las hormonas tímicas en niños desnutridos (Chandra, 1979), se puede observar incremento del receptor nuclear de glucocorticoides, por lo que el nivel nutricional podría modular la acción del receptor de glucocorticoides además de su concentración (Manary y cols., 2006).

Adicionalmente a los cambios histológicos en el timo, se ha demostrado incremento de apoptosis en timocitos CD4-CD8-, CD4+ y CD8+ de ratas desnutridas, analizado por citometría de flujo mediante la detección de anexina-V/yoduro de propidio y el ensayo TUNEL (Ortiz y cols., 2009).

Diversos estudios realizados concuerdan que la desnutrición afecta seriamente al timo y a los precursores de los linfocitos $\mathrm{T}$, esto lo convierte en un órgano principal de estudio para poder establecer una relación entre la desnutrición y la inmunodeficiencia. 


\subsection{Importancia del timo.}

El timo es colonizado por los precursores de las células T derivadas de la médula ósea y el hígado fetal, al que migran para diferenciarse.

Los timocitos en desarrollo se seleccionan positivamente, para dar origen a timocitos con receptores de células $T$ funcionales siendo CD4+ o CD8+, que corresponden al $15 \%$ de la población total de los timocitos (Savino, 2002).

La capacidad para discriminar lo propio de lo no propio es una capacidad fundamental del sistema inmunológico, el primer nivel de esta discriminación tiene lugar en el timo, en donde la mayoría de los linfocitos llevan un receptor alfa-beta de células $\mathrm{T}(\mathrm{TCR} \alpha-\beta)$ los tolerantes a los epítopos propios representados en el microambiente del timo se diferencian en timocitos CD4+ o CD8+o simples positivos. En la periferia estas subpoblaciones corresponden a los linfocitos cooperadores y citolíticos, respectivamente, capaces de reaccionar a los antígenos no propios que se presentan en el contexto del MHC de clase I y II. En fase temprana, el desarrollo de las células T alfa-beta se basa en una interacción TCR-MHC, la cual es aleloespecífica y dependiendo de su naturaleza la protege contra la apoptosis y favorece su maduración (selección positiva) o la eliminación física de los timocitos (selección negativa) (Viret y cols., 2001).

La selección positiva y negativa son procesos simultáneos que permiten el rescate de la fracción útil y la eliminación de la fracción potencialmente dañina del repertorio de TCR. De acuerdo con estudios de la diferenciación de los timocitos CD8+ in vitro, así como in vivo se han obtenido datos que demuestran que la selección positiva de 
los timocitos CD4+ es un proceso péptido-específica que se basa en el reconocimiento intratímico por TCR del complejo péptido propio-MHC propio. Esta interacción TCR-MHC provee de protección contra la apoptosis inducida (Viret y Janeway, 1999).

La selección negativa consiste en la eliminación selectiva de timocitos potencialmente autorreactivos o incompetentes en el organismo mediante apoptosis, que es el proceso fisiológico normal que controla el repertorio del sistema inmunológico. Sin embargo, la decisión de iniciar la cascada apoptótica depende de un balance entre factores de sobrevivencia y factores de muerte (Kerr y cols., 1994).

\subsection{Estudio de la desnutrición en modelos experimentales.}

Los efectos de la desnutrición en el sistema inmunológico han sido estudiados en modelos experimentales, para controlar las condiciones que pueden interferir en los efectos de la desnutrición sobre el sistema inmunológico, como la presencia de infecciones (Ortiz y cols., 1996).

Los modelos experimentales permiten fijar la variable nutricional y determinar cuáles son los procesos intratímicos que provocan la depresión de la inmunidad celular (Feliu y Slobodianik, 2002; Pallaro, 1997). El modelo experimental en rata posibilita la generación de hipótesis que podrán ser referidas en el humano (Jambon y cols., 1988).

La desnutrición por competencia de alimento durante la lactancia permite estudiar los efectos de la desnutrición en el sistema inmunológico utilizando modelos 
experimentales, permitiendo controlar condiciones que pudieran interferir en los efectos propios de la desnutrición en el sistema inmunológico. Consiste en colocar mayor número de crías por nodriza, que durante el periodo de lactancia recibirán la misma calidad de leche, pero en menor cantidad que las crías del grupo testigo o crías bien nutridas. Este modelo toma gran importancia, ya que en dicha desnutrición se muestran diversos síntomas que son similares a las características clínicas de los niños desnutridos de tercer grado (Ortiz y cols., 1996).

\subsection{Características de la apoptosis.}

La muerte celular programada o apoptosis corresponde a una secuencia de eventos intracelulares que llevan a la muerte celular. Se ha demostrado que la apoptosis es

necesaria en algunas condiciones fisiológicas tales como la embriogénesis, la homeostasis del sistema inmunológico, la eritropoyesis, etc. La muerte de las células por apoptosis es un evento fundamental en el desarrollo y el mantenimiento de la homeostasis celular (Brunner y Mueller, 2003).

La apoptosis inicia por una fase reversible de pre-compromiso y la célula se caracteriza por un alto nivel de segundos mensajeros. La fase de compromiso a continuación es irreversible, aun cuando haya desaparecido el estímulo que provocó la inducción a la apoptosis. La mayoría de las veces, la muerte celular por apoptosis requiere la síntesis de macromoléculas y la inhibición de su síntesis puede prevenirla (Guchelaar y cols., 1997). 
La célula presenta cambios morfológicos importantes durante la apoptosis, su volumen disminuye, pero aumenta su densidad (compactación celular). Posteriormente, la cromatina se condensa a lo largo de la membrana nuclear, los organelos celulares permanecen intactos y se pierde el potencial electroquímico intermembranal de la mitocondria $(\Delta \psi)$. Más tarde, la cromatina se desintegra en pequeños fragmentos y se forman pequeñas vesículas que contienen los restos celulares (cuerpos apoptóticos) que serán fagocitados por células especializadas, lo que evita la respuesta inflamatoria y el daño celular a las células vecinas. Una de las características más importantes de la muerte celular programada es la activación de una endonucleasa, que da lugar a fragmentos de ADN de 180 a 200 pares de bases o múltiplos de estos números que al analizarlos por electroforesis, las bandas de ADN dan la apariencia de una escalera. Las células apoptóticas pueden ser analizadas por citometría de flujo y se puede separar de otras células por centrifugación en un gradiente de densidad (Desoize y Sen, 1992).

\subsection{Activación de caspasas.}

Al estudiar la apoptosis en el nemátodo Caenorhabditis elegans, se determinó que el gen ced-3 codifica una cisteínproteasa necesaria para el desarrollo de la muerte celular. CED-3 tiene identidad en la secuencia con la enzima convertidora de interleucina 1-beta (ICE, también conocida como caspasa-1), se han caracterizado al menos 14 cisteínproteasas, agrupados en una familia denominada caspasas. Las caspasas se caracterizan por la alta especificidad para el ácido aspártico en la 
posición P1. Todas las caspasas contienen un sito activo conservado: glutamina (Q) alanina (A) - cisteína (C) - X - glicina (G), en donde X es Q, G o arginina (R). Las caspasas se sintetizan como proenzimas inactivas, dado por la presencia de un péptido $\mathrm{N}$-terminal, llamado prodominio, junto con una subunidad grande y una pequeña. Las estructuras cristalinas tanto de la caspasa-1, como de la caspasa-3 muestran que la enzima activa es un heterotetrámero (Cohen, 1997) compuesto de dos subunidades idénticas de $\sim 20$ kDa más dos subunidades idénticas de $\sim 10$ kDa. Estas subunidades pueden originarse por escisión mediada por otras caspasas (Rotonda y cols., 1996).

La activación de las caspasas durante la apoptosis provoca la hidrólisis de sustratos celulares críticos, incluyendo a la polimerasa, lo que ocasiona los dramáticos cambios morfológicos provocados por la apoptosis. La apoptosis inducida por CD95 (Fas/APO-1) y el factor de necrosis tumoral activa a la caspasa-8 (MACH/FLICE/Mch5), que tiene un extremo N-terminal con el dominio FADD (dominio de muerte asociado a Fas) ligado a dominios efectores de muerte que actúan como el punto de unión entre los receptores de muerte celular y la activación de las caspasas. La importancia del prodominio de las caspasas en la regulación de la apoptosis reside en el reconocimiento de moléculas adaptadoras, como RAIDD, el cual se une al prodominio de la caspasa-2 y recluta al complejo de señalización. Las células inician el proceso de apoptosis seguida de la activación de los receptores, posterior a ello se origina la activación en cascada de las caspasas, alcanzando la 
cima de la cascada apoptótica con la posible activación de las caspasas -8 y -10 (Cohen, 1997).

En los linfocitos, la activación de caspasas puede inducirse por dos vías distintas, una asociada a cambios en la permeabilidad mitocondrial y otra a señales originadas en los receptores de muerte celular localizados en la membrana plasmática [llustración 3]. Si los linfocitos se ven privados de los estímulos necesarios para su supervivencia, tales como factores de crecimiento o coestimuladores, se produce un incremento rápido de la permeabilidad de las membranas mitocondriales y se liberan al citoplasma varias proteínas, como el citocromo c. Cuando el citocromo c es liberado de la mitocondria interacciona con el factor activador de la apoptosis (APAF1) para formar el apoptosoma, que inicia la escisión de la procaspasa-9, activándola. Esta forma de apoptosis también se llama muerte celular "por abandono", lo que implica que muchas células serán programadas para morir a menos que reciban estímulos de supervivencia, de tal forma que mueren si son abandonadas (Fraker y Lill-Elghanian, 2004).

La otra vía que está involucrada en la activación de la apoptosis, está a cargo del receptor FAS, perteneciente a la familia del factor de necrosis tumoral (TNF-R). Éste contiene un dominio intracelular de "muerte" que tiene una función fundamental en el desencadenamiento de la apoptosis. El ligando de FAS (FASL) es un miembro de la familia de las citocinas TNF. FAS juega un papel crítico en el sistema inmunológico, en la autoinmunidad y en el desarrollo de tumores. FAS desencadena la apoptosis 
mediante el reclutamiento de FADD y la activación de la caspasa-8 (Strasser y cols., 2009).

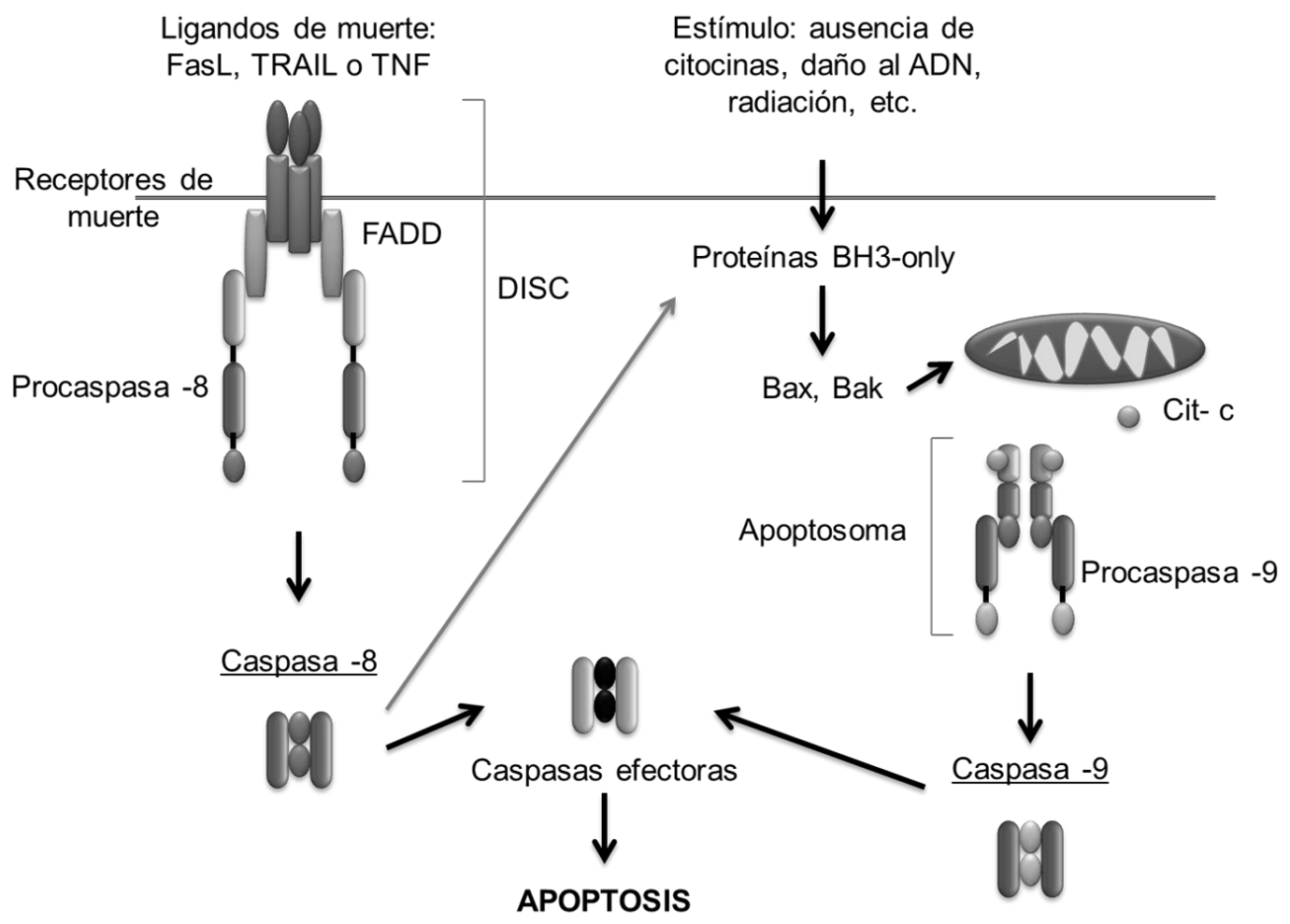

llustración 3. Vías iniciadoras de apoptosis.

La apoptosis puede ser iniciada por receptores de muerte (vía extrínseca, izquierda), que activa a la caspasa-8; o por la vía mitocondrial (vía intrínseca, derecha), que activa a la caspasa-9; ambas vías convergen en la activación de las caspasas efectoras. Basado en Xu y Shi, 2007.

\subsection{Apoptosis inducida por glucocorticoides.}

Los glucocorticoides (GCs) son hormonas esteroides de estrés, poseen en su estructura 21 carbonos, se producen en la corteza adrenal y tienen gran importancia 
en el metabolismo, principalmente de la glucosa y su control. El principal GC en mamíferos es el cortisol, excepto en roedores, en donde es reemplazado por corticosterona. Los GCs son pequeñas moléculas lipofílicas; sin embargo, algunas poseen un grupo hidroxilo, como el cortisol, lo que le permite entrar a las células a través de la membrana hacia el citoplasma, en donde se une a receptores específicos (Seckl, 1997). Existen diferentes estresores, p.ej., los cambios ambientales, estado nutricional, infecciones, etc. Los estresores inician una respuesta compleja de estrés a nivel fisiológico, endocrino y metabólico, como parte de un mecanismo de protección del organismo (Mostl y Palme, 2002). Estas reacciones se conservan en la mayoría de las especies animales, incluyendo al humano (Breuner y Orchinik, 2002).

A nivel molecular los GCs forman complejos con receptores específicos que migran al núcleo, los complejos interactúan con sitios específicos en el ADN, lo que resulta en la regulación positiva y/o negativa de varios genes implicados en la respuesta inflamatoria e inmunológica. A nivel celular los GCs inhiben el acceso de los leucocitos a sitios inflamatorios, interfieren con las funciones de los leucocitos, las células endoteliales, fibroblastos y suprimen la producción y los efectos de factores humorales involucrados en la respuesta inflamatoria (Boumpas y cols., 1993).

Los timocitos son muy sensibles a GCs, pero los más afectados son los timocitos CD4+CD8+, incrementando su apoptosis (Ortiz y cols., 2009).

Se ha aceptado que la apoptosis dependiente de GCs es mediada directamente por la unión a su receptor intracelular (GCR) y su dimerización. El complejo hormona- 
receptor se transloca al núcleo, donde modula la expresión génica por la interacción directa con los elementos de respuesta a glucocorticoides (GREs) o bien interaccionando con otros factores de transcripción (Schaaf y Cidlowski, 2002). Sin embargo a dosis altas de glucocorticoides se observan efectos rápidos, sugiriendo la existencia un efecto no genómico (Buttgereit y cols., 1999).

Diversos estudios muestran evidencias de procesos no genómicos en la apoptosis inducida por GCs. Al estudiar la expresión de GCR en las diferentes subpoblaciones de timocitos, se encontró la menor expresión en la subpoblación CD4+CD8+ que en el resto de los timocitos (Berki y cols., 2002). Adicionalmente, se encontró que la apoptosis se inducía en ausencia de la unión del complejo GC-GCR al ADN, pero que era indispensable la dimerización y la acumulación del mismo en el citosol (Sionov y cols., 2006a). Entre los eventos no genómicos involucrados en la apoptosis inducida por GCs se encuentran la generación de especies reactivas de oxígeno (ROS); la activación de fosfolipasa C (PLC), incremento de la concentración intracelular de $\mathrm{Ca}^{+2}$, incremento de ceramida y liberación de catepsina B. También ocurre la activación de la cinasa dependiente de ciclina 2 (CDK2) en la fase tardía en la exposición a glucocorticoides (Sionov y cols., 2006b) [llustración 4].

En modelos murinos se demostró que los glucocorticoides inducen la activación de las caspasas -3, -8 y -9, la degradación proteosomal y la vía lisosomal, involucrando a la catepsina B (McColl y cols., 1998; Wang y cols., 2006). Los resultados confirman que la activación de la catepsina B precede a la activación de la caspasas -3 y -8. La inhibición de la actividad de la caspasa-9 bloquea completamente a la actividad de la 
catepsina B, lo que posiciona a la caspasa-9 como clave en el inicio del proceso apoptótico inducido por glucocorticoides en timocitos.

Recientemente se ha descrito la importancia de la mitocondria en la apoptosis inducida por GCs. Se ha observado que la translocación del GCR a la mitocondria se relaciona con la sensibilidad a la apoptosis, lo que contrasta con su translocación nuclear. Sin embargo el mecanismo que media el GCR en la apoptosis es un tema de estudio. Se ha demostrado que los GCs tienen efecto en la transcripción mitocondrial y la producción de energía, además que se han encontrado GREs en el genoma mitocondrial (Sionov y cols., 2006a).

Por otra parte se muestran evidencias que la expresión génica y la síntesis de proteínas es fundamental para la apoptosis mediada por GCs. A 3 horas de la exposición a dexametasona, los timocitos CD4+CD8+ presentaron modulación en la expresión de genes codificadores de enzimas, transportadores de iones y factores de transcripción. Sin embargo las proteínas asociadas a la mitocondria fueron moduladas en menor medida (Bianchini y cols., 2006).

Tomando en cuenta estudios previos, existe contradicción en cuanto si la transcripción nuclear es imprescindible o no para la apoptosis inducida por GC. 


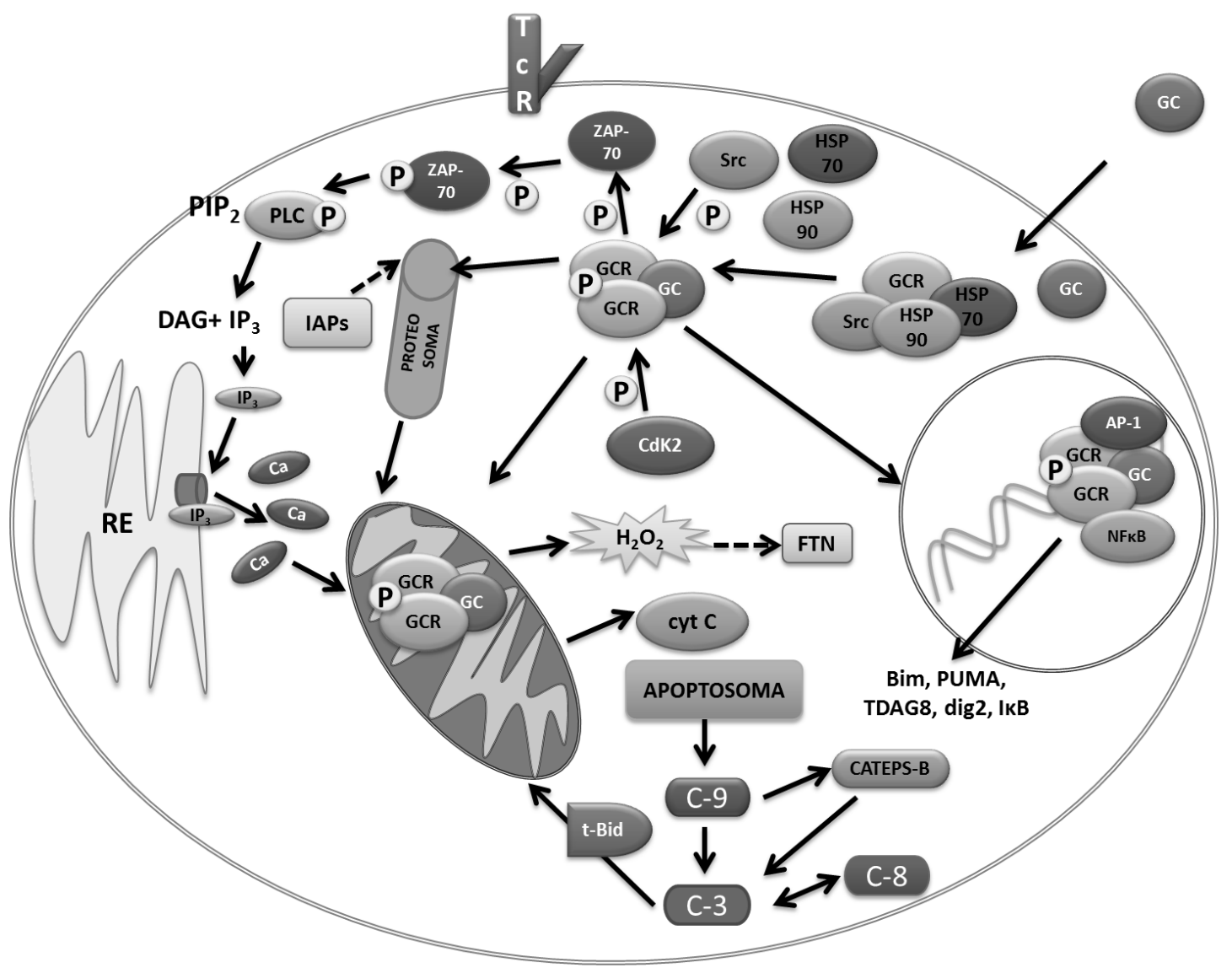

Ilustración 4. Mecanismo de inducción de apoptosis por GCs.

Los glucocorticoides inducen la muerte celular mediante la unión al receptor de glucocorticoides, este complejo induce la expresión génica, independientemente del tipo celular. Adicionalmente, en timocitos dirige la activación de la caspasa-9, la cual activa a la caspasa-3 o activa a la catepsina B (lisosomas), seguido de su liberación hacia el citoplasma y la activación de las caspasas -8 y -3, estableciendo un proceso de amplificación. Finalmente, resulta en la muerte celular, con el encogimiento celular, la exposición de fosfatidilserina y la permeabilización de la membrana. 
En el grupo de trabajo se ha estudiado a la desnutrición asociada con el incremento de apoptosis. Al inducir la apoptosis con dexametasona, un GC sintético, se observó que la fracción de timocitos susceptibles a la apoptosis fue similar en ratas bien nutridas y desnutridas (Ortiz y cols., 2001). La dexametasona tuvo mayor efecto sobre la subpoblación doble negativa en ratas desnutridas, en comparación a las ratas bien nutridas con el mismo tratamiento (Ortiz y cols., 2009). Lo que llevó a plantearse que el incremento de apoptosis asociado a la desnutrición puede estar relacionado a alteraciones del microambiente en el timo y/o a un inadecuado proceso de maduración (Ortiz y cols., 2001).

\subsection{Apoptosis y ciclo celular.}

La proliferación celular y la apoptosis son eventos opuestos; sin embargo se encuentran ligadas en el desarrollo de los timocitos y la expresión de proteínas involucradas en el ciclo celular contribuyen a su sensibilidad a la apoptosis (Xue y cols., 2008).

Adicionalmente, entre las subpoblaciones de timocitos se distinguen diferencias en la expresión de proteínas del ciclo celular. Se ha reportado que los timocitos CD4+CD8+ poseen un "estado inusual del ciclo celular", pues expresan todas las proteínas del ciclo celular estudiadas, incluyendo CDK2, ciclina A, ciclina B, p27, p21, survivina y miembros de la familia $\mathrm{Rb}$ p130 y p107. La expresión en los timocitos CD4+CD8+ cambia dependiendo a los estímulos recibidos. Se ha reportado que la 
expresión de Cdk2 es regulada negativamente después de la selección positiva (Xue y cols., 2010).

La actividad cinasa de CDK2 regula la interacción entre los miembros de la familia E2F y las proteínas Rb. Es de esta forma como las células avanzan hacia la fase $\mathrm{S}$. Las CDK fosforilan a Rb y éste libera al factor de transcripción E2F (DeGregori y cols., 1997). La actividad transcripcional de E2F controla la expresión de muchos de los genes necesarios para la progresión de la fase G1 a S (Zhu y cols., 1999). E2F1 es el único miembro de la familia E2F que media procesos apoptóticos cuando se sobre-expresa, regulando la transcripción de las caspasas -3, -8 y -9 (Nahle y cols., 2002).

E2F1 es necesario para la apoptosis de las células $T$ autoinmunes inmaduras durante la selección tímica negativa in vivo, pero no es necesario para la inducción de la apoptosis por los glucocorticoides o daño en el ADN (Zhu y cols., 1999); sin embargo se ha reportado actividad de CDK2 en CD4+CD8+, inducida por glucocorticoides, radiación, Fas-L o señalización del TCR (Granes y cols., 2004). Diversos estudios apoyan la relación entre la susceptibilidad a la apoptosis con el estado del ciclo celular. 


\section{JUSTIFICACIÓN.}

La desnutrición durante la infancia tiene un impacto importante en el crecimiento físico, mental y el desarrollo del individuo (Joao y cols., 1968). Es un problema de salud que afecta principalmente a los niños y se asocia con infecciones y muertes en menores de cinco años de edad. La inmunodeficiencia observada en la desnutrición está asociada a la atrofia tímica y a la apoptosis en timocitos, por lo que es importante estudiar el efecto de la desnutrición en este órgano para determinar las posibles causas de la susceptibilidad a infecciones en organismos desnutridos.

Se han realizado diversos estudios para determinar las causas involucradas en la inmunodeficiencia observada en niños desnutridos. Sin embargo, el estudio en humanos, es permitido hasta cierto punto y para complementarlos es necesario el uso de modelos experimentales (Barone y cols., 1993).

El método de desnutrición por competencia de alimento durante la lactancia en ratas cepa Wistar, permite estudiar los efectos de la desnutrición en el sistema inmunológico en modelos experimentales, permitiendo controlar condiciones que pudieran interferir en los efectos propios de la desnutrición en el sistema inmunológico (Ortiz y cols., 1996).

Para el estudio del efecto de la desnutrición a nivel celular se han aplicado diversas técnicas y métodos, una de las más utilizadas para el estudio a nivel celular ha sido la citometría de flujo, que ha permitido obtener información que asocia a la desnutrición con el incremento de células apoptóticas en timo y bazo (Ortiz y cols., 2009). 
Es necesario seguir realizando estudios utilizando técnicas adecuadas, que permitan aportar mayor conocimiento sobre el mecanismo de apoptosis en los linfocitos $T$ en la desnutrición, pues a pesar de los diversos estudios, no se conoce en su totalidad. Esto ayudará a conocer de manera más clara los factores que interaccionan para originar una respuesta celular que determina el destino hacia la muerte programada y con ello comprender mejor las condiciones que llevan finalmente a la inmunodeficiencia.

Estudiar la vía principal de apoptosis de los timocitos en modelos experimentales, nos permite definir la rutas bioquímicas activas y las condiciones que se relacionan con el proceso apoptótico, además de confirmar la importancia del timo como órgano linfoide en la inmunodeficiencia por desnutrición.

\section{HIPÓTESIS.}

En diversos estudios se ha demostrado que la desnutrición incrementa la apoptosis en timocitos, y debido a que la apoptosis se activa por una de las dos vías iniciadoras, se espera mayor proporción de timocitos con caspasas iniciadoras de apoptosis, en los organismos desnutridos, en comparación a los bien nutridos. 


\section{OBJETIVO GENERAL.}

Determinar la vía iniciadora de apoptosis en timocitos de ratas bien nutridas y ratas desnutridas experimentalmente, por competencia de alimento durante el periodo de lactancia.

\subsection{Objetivos particulares.}

En ratas bien nutridas (testigos) y el ratas desnutridas durante la lactancia (experimentales).

1. Evaluar la apoptosis temprana y tardía, mediante la presencia de caspasas activas.

2. Determinación de la susceptibilidad a la apoptosis en subpoblaciones de timocitos dobles negativos, CD4-CD8-; dobles positivos, CD4+CD8+; y simple positivos CD4+, CD8+, mediante la detección de caspasas activas y la pérdida de selectividad de la membrana celular.

3. Determinación la fase del ciclo celular con mayor susceptibilidad a la apoptosis, mediante la presencia de caspasas activas y cuantificación de ADN.

4. Identificar la vía iniciadora de apoptosis extrínseca e intrínseca, en cada subpoblación de timocitos, mediante la detección de las caspasas activas -8 y -9 , respectivamente. 


\section{MATERIAL Y MÉTODO.}

\subsection{Desnutrición experimental en ratas.}

En este estudio se utilizaron crías de ratas de la cepa Wistar de 21 días de edad, criadas en el Bioterio de la Universidad Autónoma Metropolitana Iztapalapa, bajo luz controlada de $12 / 12$ horas de luz/oscuridad, temperatura entre $22-25^{\circ} \mathrm{C}$ y humedad relativa de $60 \%$.

Se estudiaron cuatro grupos de ratas: bien nutridas $(B N)$, desnutridas (DN), bien nutridas tratadas con dexametasona (BN DX) y desnutridas tratadas con dexametasona (DN DX).

La desnutrición se indujo experimentalmente por competencia de alimento durante el periodo de lactancia, que comprende los primeros 21 días de vida.

Los grupos se formaron con crías de un día de edad, en donde el grupo testigo, las camadas de las ratas bien nutridas (C-BN) fueron formadas con 7 crías por nodriza, y las camadas de ratas desnutridas (C-DN) con 16 crías por nodriza. Se realizó el seguimiento del peso de las ratas durante el periodo de lactancia.

El grado de desnutrición se determinó mediante el déficit de peso de las crías de la C-DN en relación al peso alcanzado por las del grupo testigo (C-BN) al término de la lactancia. En el estudio se incluyeron crías con déficit de peso igual o mayor al $40 \%$. Al cabo de 20 días se evaluó el grado de desnutrición alcanzado. En ese día, a partir de las C-BN y C-DN, se formaron dos grupos alternos: ratas bien nutridas y ratas desnutridas que fueron tratadas con dexametasona soluble. La dexametasona se 
inyectó intraperitonealmente en una dosis proporcional al peso corporal $(25 \mathrm{mg} / \mathrm{Kg}$ de peso corporal) y se dejó actuar durante 20 horas en el organismo (Ortiz y cols., 2001).

\subsection{Obtención de timocitos.}

Al cabo de los 21 días de edad, y habiendo cumplido las 20 horas de exposición en los grupos tratados con dexametasona, la ratas fueron pesadas y se sacrificaron por dislocación cervical. Se sacrificó una rata por grupo en cada ensayo. Se extrajo el timo de cada rata, se eliminó el tejido conjuntivo y se mantuvo en solución amortiguadora de fosfatos (PBS) fría. Cada timo fue pesado y disgregado con $3 \mathrm{~mL}$ de PBS frío, utilizando una malla de plástico y un pistilo de vidrio. De la suspensión celular obtenida se tomaron $10 \mu \mathrm{L}$ y fueron incubados con $790 \mu \mathrm{L}$ de ácido acético frío al 2\% (dilución 1:80) durante 10 minutos, para realizar la cuenta celular al microscopio (Olympus, modelo BH-2) se utilizó la cámara de Neubauer.

La obtención de la cuenta celular por órgano (timo) se obtuvo al realizar el cálculo siguiente:

(n) $\left(1 \times 10^{4}\right)(80)(3)=$ número de células por timo

Donde:

$\eta=\quad$ Media celular en los cuadrantes de la cámara Neubauer.

$1 \times 10^{4}=\quad$ Factor constante.

$80=\quad$ Factor de dilución de la muestra para su conteo.

$3=\quad$ Volumen total en que se disgregó el órgano, dado en $\mathrm{mL}$. 


\subsection{Determinación de la apoptosis en timocitos.}

La apoptosis se determinó por detección de caspasas activas, utilizando el reactivo incluido en el kit FLICA (Fluorocromo Inhibidor de Caspasas. Immunochemistry Technologies, LLC) y 7-AAD.

El kit para detección de apoptosis poli-caspasas FLICA contiene el inhibidor FAMVAD-FMK, el cual es una carboxifluoresceina (FAM) derivada del ácido valinilalanilaspártico (VAD) fluorometil cetona (FMK), un potente inhibidor de actividad de caspasas, permeable a la membrana celular y no citotóxico. Cuando se adiciona a la población celular, FAM-VAD-FMK FLICA entra a cada célula y se une covalentemente al residuo activo de cisteína localizado en la subunidad grande del heterodímero de la caspasa activa, de este modo se inhibe la actividad enzimática. Debido a que los reactivos FAM-VAD-FMK FLICA llegan a unirse covalentemente a la enzima, son retenidos en la célula (Ekert y cols., 1999; Thornberry y cols., 1997). FAM-FLICA verde se excita a $490 \mathrm{~nm}$ y emite fluorescencia a $530 \mathrm{~nm}$.

Las actinomicinas son constituyentes biológicos activos compuestos de un cromóforo (2-Amino-4,6 Dimetilfenoxazono-3) y de pentapéptidos cíclicos. Se trata de antibióticos de origen bacteriano, históricamente caracterizados en los ascomicetos del suelo. Las actinomicinas forman complejos estables con el ácido desoxiribonucleico (ADN) bicatenario, pero no con el ácido ribonucleico (ARN) bicatenario, híbridos ARN-ADN, ADN ni ARN monocatenarios (Schmid y cols., 1992). El 7-Amino Actinomicina D (7-AAD) es un análogo de la actinomicina, que contiene un grupo amino substituido en posición 7 del cromóforo. El 7-AAD se intercala entre 
las capas de bases citosina/guanina del ADN (Lecoeur y cols., 1997). Las propiedades espectrales del 7-AAD lo convierten en una molécula especialmente adecuada para el análisis por citometría de flujo (Schmid y cols., 1992). La absorción máxima del complejo 7-AAD/ADN es compatible con la longitud de onda de excitación azul de 488 nm de los citómetros equipados con láser de argón (Zelenin y cols., 1984). El pico de emisión de fluorescencia en el rojo profundo (de 635 a 675 nm) del complejo 7-AAD/ADN permite una utilización óptima de este intercalante cuando se combina con anticuerpos conjugados al isotiocianato de fluoresceína (FITC) y a la R ficoeritrina (PE) (Schmid y cols., 1992). En efecto y contrariamente al yoduro de propidio, que es otra molécula fluorescente utilizada como marcador del ADN, el complejo 7-AAD/ADN presenta una imbricación reducida del espectro de emisión con el FITC y la PE.

Las subpoblaciones de timocitos se identificaron con anticuerpos contra los coreceptores CD4-APC (Aloficocianina: APC) y CD8-PE (Ficoeritrina: PE).

Para identificar las fases del ciclo celular, las células marcadas con FLICA policaspasas se fijaron y se trataron con Ribonucleasa A (ARNasa, $1 \mathrm{mg} / \mathrm{mL}$ ) para después identificar las fases del ciclo celular por cuantificación de ADN, utilizando 7AAD como fluorocromo intercalante de ADN.

Para la lectura de las muestras se utilizó un citómetro de flujo BD FACSCalibur (Becton-Dickinson) [llustración 5], el cual cuenta con un sistema de citometría de flujo de 4 colores y de dos láser, cuenta con la capacidad de realizar el análisis y separación de células. Está equipado con un láser azul de argón (15 mW) que emite 
a $488 \mathrm{~nm}$, y un láser diodo de helio-neón que emite a $635 \mathrm{~nm}$. El FACSCalibur tiene dos detectores para la dispersión de la luz láser y cuatro detectores para fluorescencia en verde, naranja, rojo y rojo lejano y filtros de paso de banda 530/30 nm (FL1), 585/42 nm (FL2), filtro de paso largo LP670 nm (FL3) y filtro 661/16 nm (FL4).

Al término de la lectura por citometría de flujo de cada muestra, las células analizadas pueden visualizarse en gráficas (de puntos, densidad e histogramas, entre otros) y mediante las cuales se analizan los parámetros de interés en la población deseada.

Inicialmente se delimitó una región para determinar a la población de interés. El análisis de datos se realizó utilizando los programas informáticos para citometría de flujo: Summit v4.0 y WinMDI v2.8.

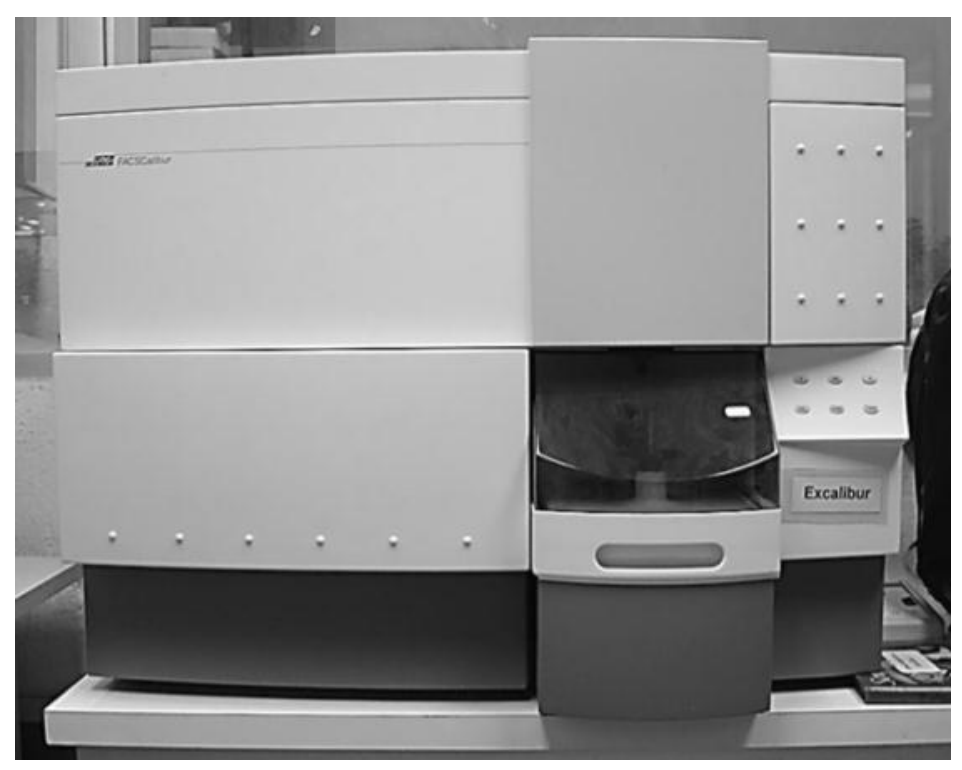

Ilustración 5. Citómetro de Flujo BD FACSCalibur. 


\subsection{Estudio para la identificación de caspasas en timocitos.}

Una vez obtenida la suspensión celular, las células se lavaron con solución de PBS-

Albúmina al $1 \%$. Se colocaron $1 \times 10^{6}$ células en tubos de $5 \mathrm{ml}$ (Falcon $\AA$ ). Se tiñeron con el reactivo de FLICA poli-caspasas, según el procedimiento descrito en el manual del kit FLICA ${ }^{\mathrm{TM}}$. Después de la incubación con el reactivo de FLICA (60 min), las muestras fueron lavadas y marcadas con $50 \mu \mathrm{L}$ de 7 -AAD $(10 \mu \mathrm{g} / \mathrm{mL})$ por 10 minutos. Se analizaron 10000 células por muestra por citometría de flujo, se identificó al reactivo de FLICA poli-caspasas en FL1 y al 7-AAD en FL3. Los timocitos fueron fijados para su posterior análisis por cuantificación de ADN.

\subsection{Estudio de la apoptosis temprana y tardía en subpoblaciones de timocitos.}

Las células se lavaron con solución de PBS-albúmina al $1 \%$. Se colocaron $1 \times 10^{6}$ células en tubos de $5 \mathrm{ml}$ (Falcon $\left.{ }^{\circledR}\right)$. Se tiñeron con $2 \mu \mathrm{L}$ de anticuerpos anti CD4APC y anti CD8-PE, después de 20 min de incubación con estos anticuerpos, las muestras fueron lavadas con PBS y marcadas e incubadas con el reactivo de FLICA poli-caspasas (60 min), después las muestras fueron lavadas y marcadas con $50 \mu \mathrm{L}$ de 7-AAD $(10 \mu \mathrm{g} / \mathrm{mL})$, por 10 minutos. Se analizaron 10000 células por citometría de flujo, detectando el reactivo de poli-caspasas FLICA en FL1, el 7-AAD en FL3, anti CD4-APC en FL4 y anti CD8-PE en FL2. 


\subsection{Estudio de la apoptosis en las fases del ciclo celular, por cuantificación de ADN e identificación de caspasas.}

Se utilizaron timocitos previamente marcados y fijados con el reactivo de FLICA policaspasas. Cada muestra fue tratada con $50 \mu \mathrm{L}$ de ARNasa $(1 \mathrm{mg} / \mathrm{mL})$, por 30 minutos. Al término se incubaron con $25 \mu \mathrm{L}$ de $7-A A D(10 \mu \mathrm{g} / \mathrm{mL})$, por 10 minutos. Se analizaron 20000 células por muestra por citometría de flujo.

\subsection{Estudio de la apoptosis temprana en las subpoblaciones de timocitos, mediante la identificación de las caspasas iniciadoras de apoptosis $\mathbf{- 8}$ y $\mathbf{- 9}$.}

Se colocaron $1 \times 10^{6}$ células lavadas en tubos de $5 \mathrm{ml}$ (Falcon $\left.{ }^{\circledR}\right)$. Se tiñeron con $2 \mu \mathrm{L}$ de anticuerpos anti CD4-APC y anti CD8-PE (20 min). Después las muestras fueron lavadas con PBS y marcadas con el reactivo de FLICA caspasas específicas -8 y -9 para cada muestra, según el procedimiento establecido en el manual del kit FLICA ${ }^{\mathrm{TM}}$. Después de la incubación con el reactivo de FLICA (60 min), las muestras fueron lavadas y marcadas con $50 \mu \mathrm{L}$ de $7-\mathrm{AAD}(10 \mu \mathrm{g} / \mathrm{mL})$ por 10 minutos. Se analizaron 10000 células por muestra por citometría de flujo.

\subsection{Análisis estadístico.}

Se estudiaron 6 muestras por grupo. La comparación entre ellas se realizó aplicando la prueba de análisis no paramétrico $U$ de Mann-Whitney, teniendo en cuenta un nivel de significancia de 0.05 . 


\section{RESULTADOS.}

\subsection{Datos de las muestras estudiadas.}

Se utilizaron ratas de 21 días de edad distribuidas en 4 grupos: BN, DN, BN DX y DN DX.

El peso de las ratas $B N$ fue de $52.2 \pm 2.5$ gramos; en DN $23.7 \pm 2.7$ gramos (promedio $\pm \mathrm{DE}$ ) [Cuadro 1]. El peso de las ratas DN fue significativamente menor respecto al grupo $\mathrm{BN}$.

El peso de las ratas del grupo DN DX $(23.3 \pm 2.2$ gramos $)$ fue significativamente menor que en el grupo BN DX (46.6 \pm 4.6 gramos); no hubo diferencia estadísticamente significativa entre los grupos DN y DN DX; tampoco entre BN y BN DX.

El peso del timo en el grupo DN (84.8 \pm 35.0 miligramos) fue significativamente menor que en las ratas del grupo BN (192.0 \pm 54.0 miligramos); pero no hubo diferencia al compararlo con el grupo DN DX. En el grupo BN DX $(88.8 \pm 16.0$ miligramos) el peso del timo fue significativamente menor que en el grupo BN; pero no hubo diferencia al compararlo con las ratas DN DX (81.2 \pm 41.9 miligramos).

El número de células por timo disminuyó significativamente en el grupo DN (240.7 \pm 112.5 millones) respecto al grupo $\mathrm{BN}$ (551.2 \pm 163.1 millones); de igual forma disminuyó en los grupos tratados con dexametasona, respecto a los grupos sin tratamiento. Al comparar a los grupos BN DX y DN DX no se encontró diferencia. 


\begin{tabular}{|c|c|c|c|c|c|c|c|c|}
\hline & \multicolumn{4}{|c|}{ NO TRATADAS } & \multicolumn{4}{|c|}{ TRATADAS CON DEXAMETASONA } \\
\hline & \multicolumn{2}{|l|}{ BN } & \multicolumn{2}{|l|}{ DN } & \multicolumn{2}{|l|}{ BN } & \multicolumn{2}{|l|}{ DN } \\
\hline & PROMEDIO & D.E. & PROMEDIO & D.E. & PROMEDIO & D.E. & PROMEDIO & D.E. \\
\hline Peso corporal (g) & 52.2 & 2.5 & $23.7^{a}$ & 2.7 & 46.6 & 4.6 & $23.3^{b}$ & 2.0 \\
\hline Déficit de peso (\%) & & & 54.4 & 4.8 & & & 47.9 & 6.9 \\
\hline Peso del timo (mg) & 192.0 & 54.0 & $84.8^{a}$ & 35.0 & $88.6^{a}$ & 16.0 & 81.2 & 41.9 \\
\hline Déficit de peso del timo & $\%)$ & & 55.2 & 13.0 & & & 38.9 & 28.2 \\
\hline Células por timo $\left(x 10^{6}\right)$ & 551.2 & 163.1 & $240.7^{a}$ & 112.5 & $87.6^{a}$ & 39.5 & $69.8^{c}$ & 34.4 \\
\hline Proporción celular & 3.0 & 1.1 & 2.8 & 0.6 & $0.9^{a}$ & 0.4 & $1.2^{\mathrm{c}}$ & 0.9 \\
\hline
\end{tabular}

Cuadro 1. Datos de las muestras estudiadas.

Se incluye el promedio del peso corporal, del timo y la número de células por órgano, obtenido en las muestras estudiadas para los grupos BN, DN y grupos tratados con dexametasona $(25 \mathrm{mg} / \mathrm{Kg}$ de peso corporal) $(\mathrm{n}=6)$. La proporción celular indica la relación de timocitos $\left(\times 10^{6}\right)$ correspondientes en un miligramo de tejido. $\mathbf{a}: \mathrm{p}<0.05$ comparado con el grupo BN; $\mathbf{b}$ : $p<0.05$ comparado con el grupo BN DX; c: $p<0.05$ comparado con el grupo DN. 
No se encontró diferencia en la proporción de timocitos por miligramo de timo, entre los grupos BN y DN. Los grupos tratados con dexametasona mostraron disminución de la proporción celular en comparación a sus respectivos grupos sin tratamiento. No hubo diferencia en la proporción de timocitos entre ambos grupos con tratamiento.

\subsection{Análisis de la apoptosis en timocitos.}

Selección de la región de análisis.

Se graficó el parámetro de dispersión frontal (Forward Scatter: FSC) contra el parámetro de dispersión lateral (Side Scatter: SSC), para identificar a los linfocitos en función de su tamaño y complejidad interna, respectivamente. La región de timocitos se muestra en la ilustración 6 .

Posterior a la identificación de la población de timocitos, se graficó la señal emitida por FLICA poli-caspasas (FL1), para la determinación de la actividad de caspasas, contra la señal emitida por el 7-AAD (FL3), se analizó únicamente la población de timocitos previamente delimitada, se obtuvo una gráfica de puntos en donde se delimitaron las regiones para la identificación de timocitos vivos, en apoptosis temprana, tardía y necrosis [llustración 6]. Este análisis se realizó para cada muestra en los cuatro grupos: BN, DN, BN DX y DN DX, los valores se expresan en porcentajes respecto a la población total de timocitos. Se analizaron seis muestras por grupo. 

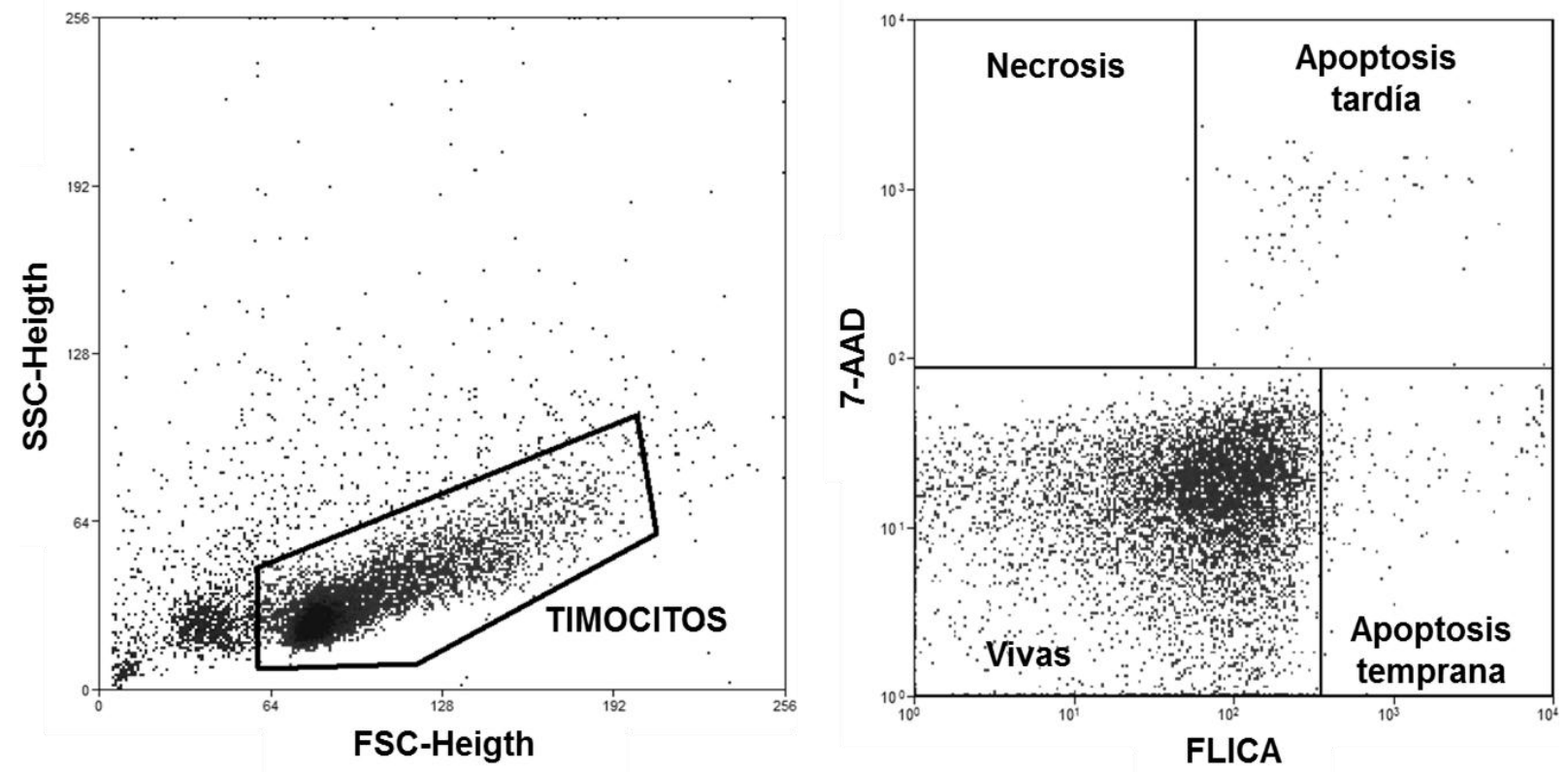

llustración 6. Gráficas de puntos para la identificación de timocitos.

Izquierda: Identificación de la población total de timocitos. Se obtiene al graficar el parámetro Forward Scatter (FSC) contra SideScatter (SSC), los cuales permiten identificar a los timocitos por su tamaño celular y su complejidad interna, respectivamente. Derecha: Gráfica para la identificación de timocitos vivos, en apoptosis temprana, tardía y necrosis, obtenida al graficar la fluorescencia recibida en FL1 (FLICA poli-caspasas) contra FL3 (7-AAD), a partir de la población de timocitos. Los timocitos vivos se distinguen al no presentar marcaje para caspasas (FLICA poli-caspasas), ni para 7-AAD (membrana celular selectiva); los timocitos en apoptosis temprana presentan marcaje sólo para FLICA poli-caspasas; Ios timocitos en apoptosis tardía presentan marcaje para caspasas y para 7-AAD; los timocitos necróticos sólo presentan marcaje para 7-AAD.

En las ratas BN se obtuvo $93.6 \pm 2.2 \%$ de timocitos vivos; $3.1 \pm 1.9 \%$, en apoptosis temprana; $2.7 \pm 2.0 \%$, en apoptosis tardía; y $0.7 \pm 0.6 \%$ de necrosis (promedio \pm $\mathrm{DE})$. 
En las ratas DN se obtuvo $83.8 \pm 1.3 \%$ de timocitos vivos; $7.5 \pm 3.9 \%$ en apoptosis temprana; $8.5 \pm 3.5 \%$ en apoptosis tardía; y $1.0 \pm 0.7 \%$ de necrosis.

En las ratas BN DX se obtuvo $27.3 \pm 17.9 \%$ de timocitos vivos; $15.2 \pm 7.0 \%$, en apoptosis temprana; $53.8 \pm 23.1 \%$, en apoptosis tardía; y $4.9 \pm 5.8 \%$ de necrosis. En el grupo DN DX se obtuvo $20.2 \pm 2.4 \%$ de timocitos vivos; $13.8 \pm 5.8 \%$, en apoptosis temprana; $65.3 \pm 4.5 \%$, en apoptosis tardía; y $1.7 \pm 0.6 \%$ de necrosis.

Al comparar el grupo DN respecto al grupo BN, se observó disminución de timocitos vivos e incremento en la apoptosis temprana y tardía. Los grupos tratados con dexametasona mostraron incremento significativo de timocitos en apoptosis temprana, tardía y necrosis, así como disminución de timocitos vivos, respecto a los grupos nos tratados. Mientras que no hubo diferencia entre los grupos BN DX y DN DX [Figura 1]. 


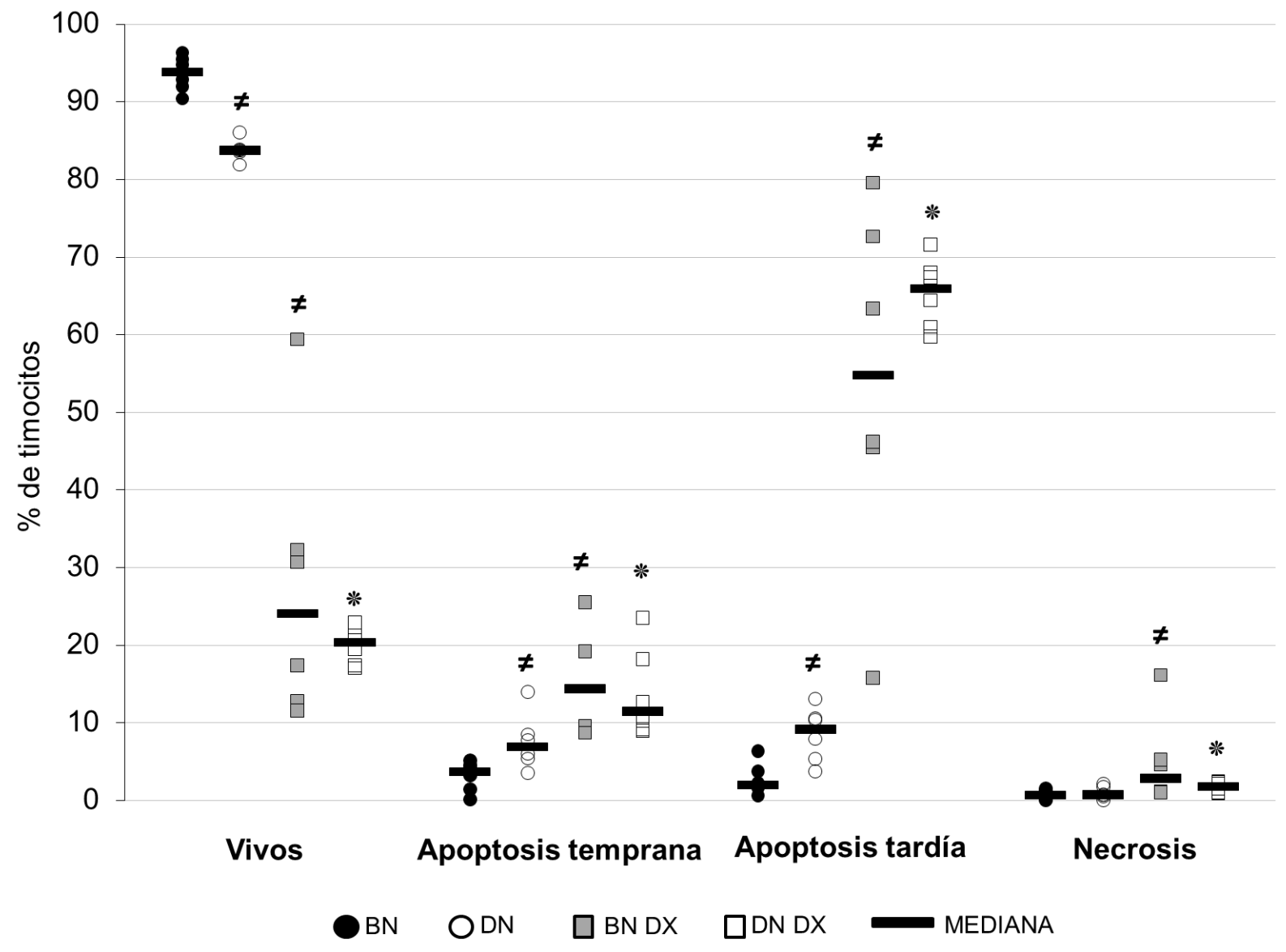

Figura 1. Proporción de timocitos vivos, en apoptosis temprana, tardía y necrosis.

Se observó disminución de timocitos vivos en el grupo DN e incremento en apoptosis temprana y tardía, en comparación con el grupo BN. Los grupos tratados presentaron disminución de timocitos vivos e incremento en apoptosis temprana y tardía, en comparación con los grupos sin tratamiento $(n=6) . \neq p<0.05$ comparado con el grupo $B N ; * 0<0.05$ comparado con el grupo DN. 


\subsection{Análisis de la apoptosis temprana y tardía en subpoblaciones de timocitos.}

Selección de la región de análisis.

A partir de la población de timocitos, se identificaron a las cuatro subpoblaciones analizadas: CD4-CD8-, CD4+CD8+, CD4+ y CD8+ [llustración 7].

Para la determinación de la apoptosis por actividad de caspasas, se graficó la señal recibida de FLICA poli-caspasas (FL1) contra la señal recibida por el 7-AAD (FL3), para cada subpoblación de timocitos, de esta forma se obtuvo una gráfica de puntos en donde se delimitaron las regiones para el análisis de las células vivas, células en apoptosis temprana, tardía y necrosis [llustración 7] para cada subpoblación.

Únicamente se analizaron los grupos sin tratamiento, debido a que la dexametasona tuvo el efecto de disminuir al mínimo la subpoblación de timocitos CD4+CD8+, por lo que no pudieron ser analizados.

Los resultados muestran el porcentaje de células en cada subpoblación respecto al total de timocitos, para BN y DN. Se analizaron seis muestras por grupo. 

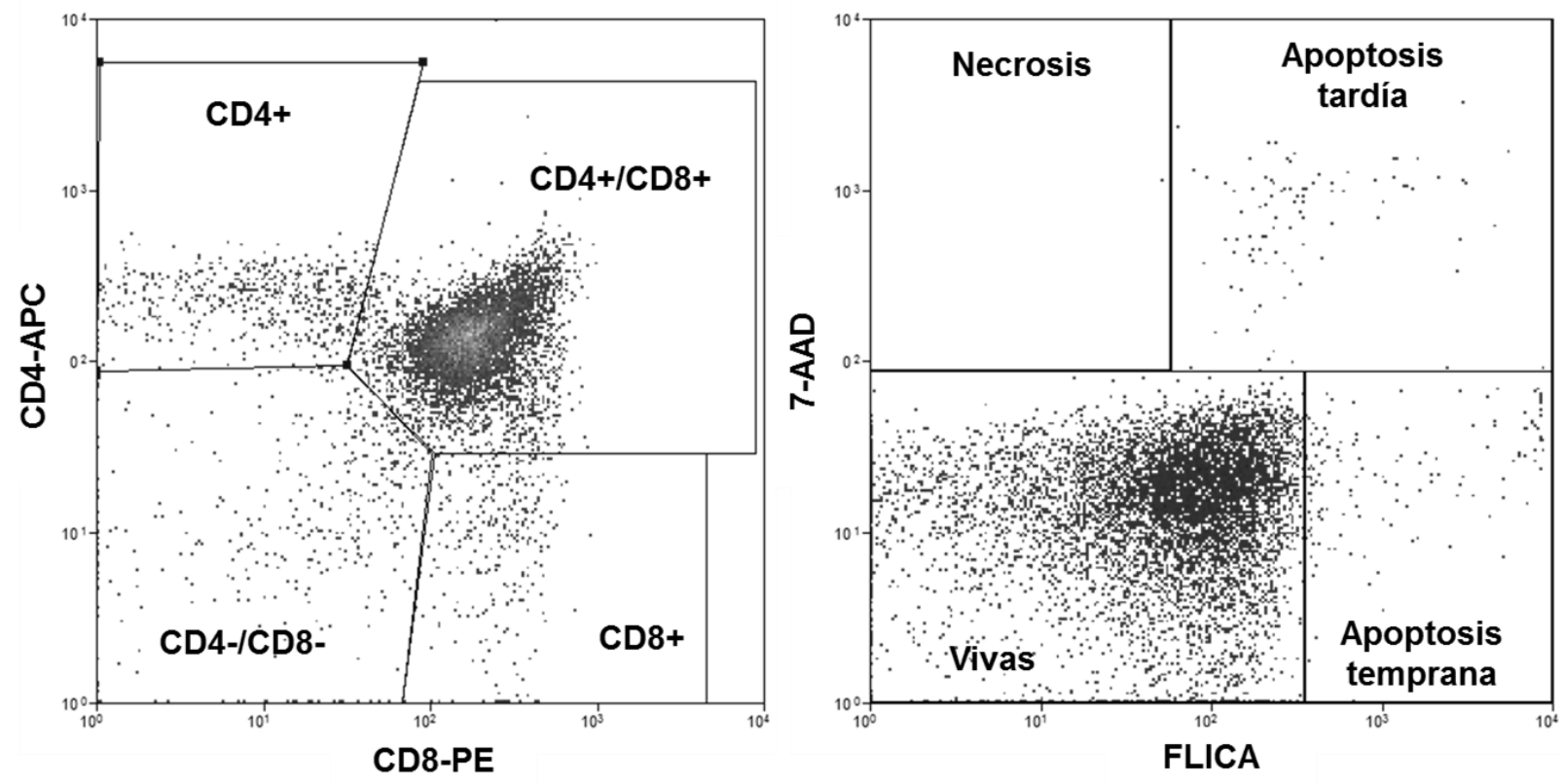

Ilustración 7. Gráfica para la identificación de subpoblaciones de timocitos.

Izquierda: Regiones para la identificación de las subpoblaciones de timocitos CD4-CD8-, CD4+CD8+, CD4+ y CD8+, marcados con anti CD8-PE y anti CD4-APC. Derecha: Regiones para la identificación de timocitos vivos, en apoptosis temprana, tardía y necrosis, analizadas para cada subpoblación.

En el grupo BN se obtuvo $8.9 \pm 2.2 \%$ de timocitos CD4-CD8-; $64.8 \pm 3.4 \%$, en CD4+CD8+; $11.9 \pm 3.2 \%$, en CD4+; y $14.0 \pm 2.2 \%$, en CD8+ (promedio \pm DE).

En el grupo DN se obtuvo $15.5 \pm 3.8 \%$ de timocitos CD4-CD8-; $70.6 \pm 4.4 \%$, en CD4+CD8+; $7.2 \pm 1.7 \%$, en CD4+; y $7.2 \pm 2.1 \%$, en CD8+.

Se encontró incremento en la proporción de timocitos CD4-CD8- y CD4+CD8+ en el grupo DN respecto al grupo BN; mientras que se observó disminución en las subpoblaciones de CD4+ y CD8+ [Figura 2]. 


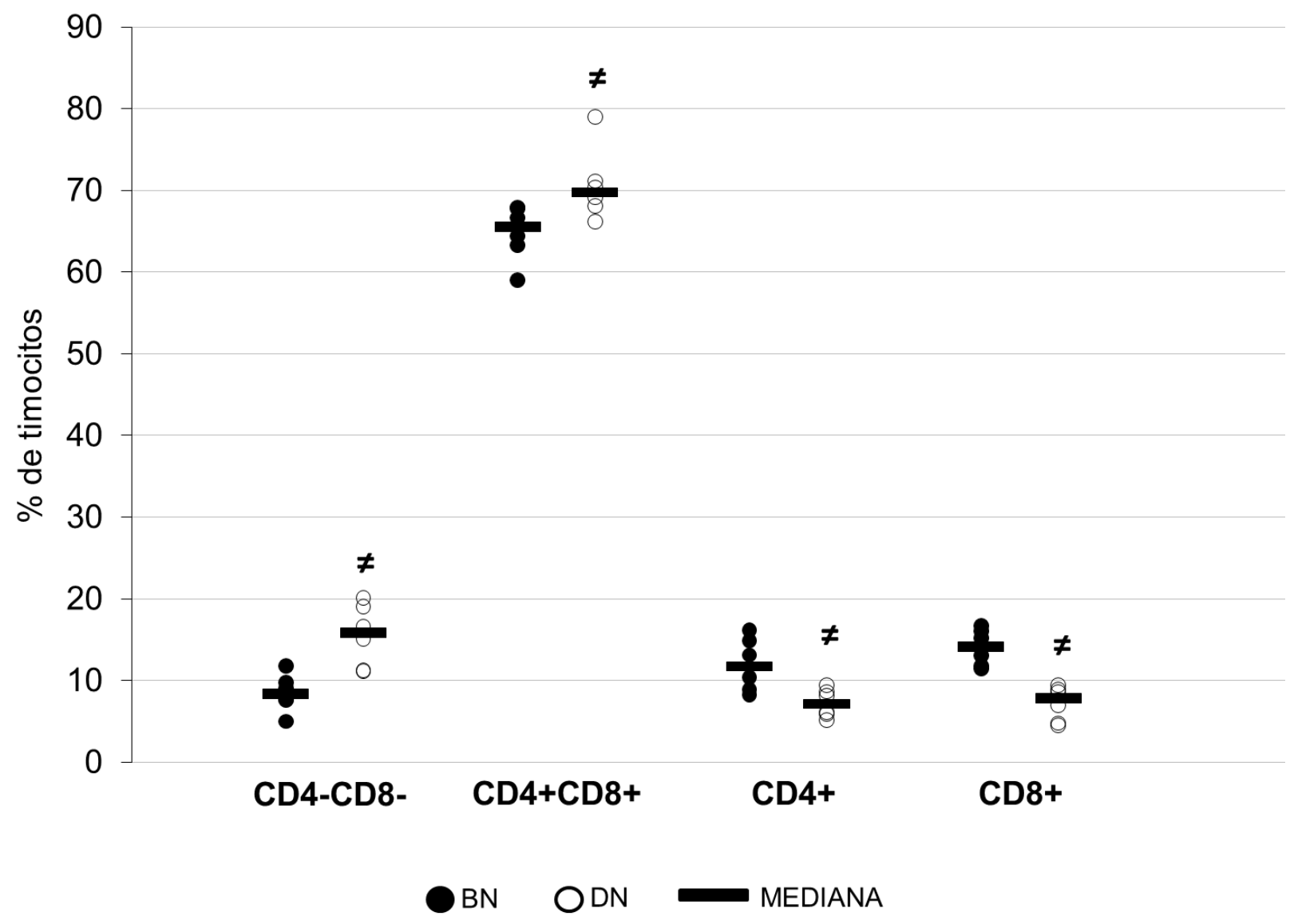

Figura 2. Proporción de timocitos en cada subpoblación en los grupos BN y DN.

Timocitos en cada subpoblación para el grupo de ratas bien nutridas (BN) y desnutridas (DN). Se encontró incremento significativo de timocitos CD4-CD8- y CD4+CD8+; en el grupo $D N$ respecto al grupo $B N(n=6) . \neq p<0.05$ comparado con el grupo $B N$.

Posteriormente se analizó el porcentaje de timocitos vivos, en apoptosis temprana y tardía en cada subpoblación de timocitos en los grupos BN y DN. Los resultados muestran porcentajes respecto al total de timocitos en cada subpoblación. Se analizaron seis muestras por grupo. 
En el grupo BN, la subpoblación CD4-CD8- presentó $89.4 \pm 6.1 \%$ de timocitos vivos; $2.9 \pm 2.1 \%$, en apoptosis temprana; $7.9 \pm 4.2 \%$ en apoptosis tardía (promedio \pm $\mathrm{DE})$.

En el grupo DN la subpoblación CD4-CD8- presentó $64.9 \pm 9.7 \%$ de timocitos vivos; $7.1 \pm 1.8 \%$, en apoptosis temprana; $27.1 \pm 8.7 \%$, en apoptosis tardía.

En el grupo DN se observó disminución en la proporción de timocitos CD4-CD8vivos, así como incremento en la apoptosis temprana y tardía, respecto al grupo BN [Figura 3].

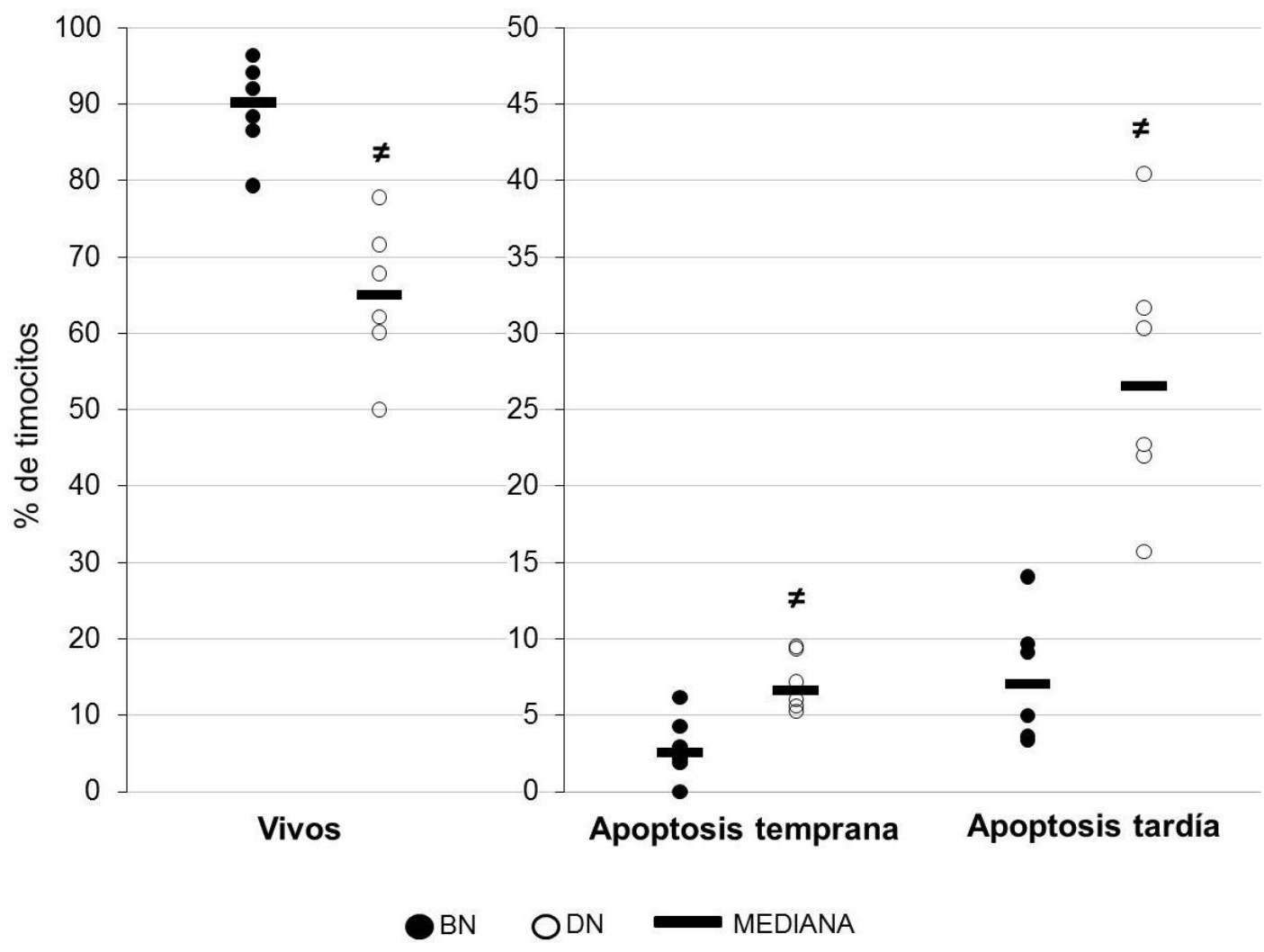

Figura 3. Análisis de apoptosis en timocitos CD4-CD8- para los grupos BN y DN.

El grupo DN presentó disminución de timocitos CD4-CD8- vivos, así como incremento en la apoptosis temprana y tardía $(n=6)$. $\neq p<0.05$ comparado con el grupo BN. 
En el grupo BN, la subpoblación CD4+CD8+ presentó $96.8 \pm 1.9 \%$ de timocitos vivos; $2.6 \pm 2.1 \%$, en apoptosis temprana; $0.4 \pm 0.2 \%$ en apoptosis tardía (promedio $\pm \mathrm{DE})$.

En el grupo DN, la subpoblación CD4+CD8+ presentó $90.1 \pm 3.2 \%$ de timocitos vivos; $8.6 \pm 2.6 \%$, en apoptosis temprana; $1.2 \pm 0.9 \%$, en apoptosis tardía.

En el grupo DN se observó disminución en la proporción de timocitos vivos e incremento en la apoptosis temprana, respecto al grupo BN [Figura 4].

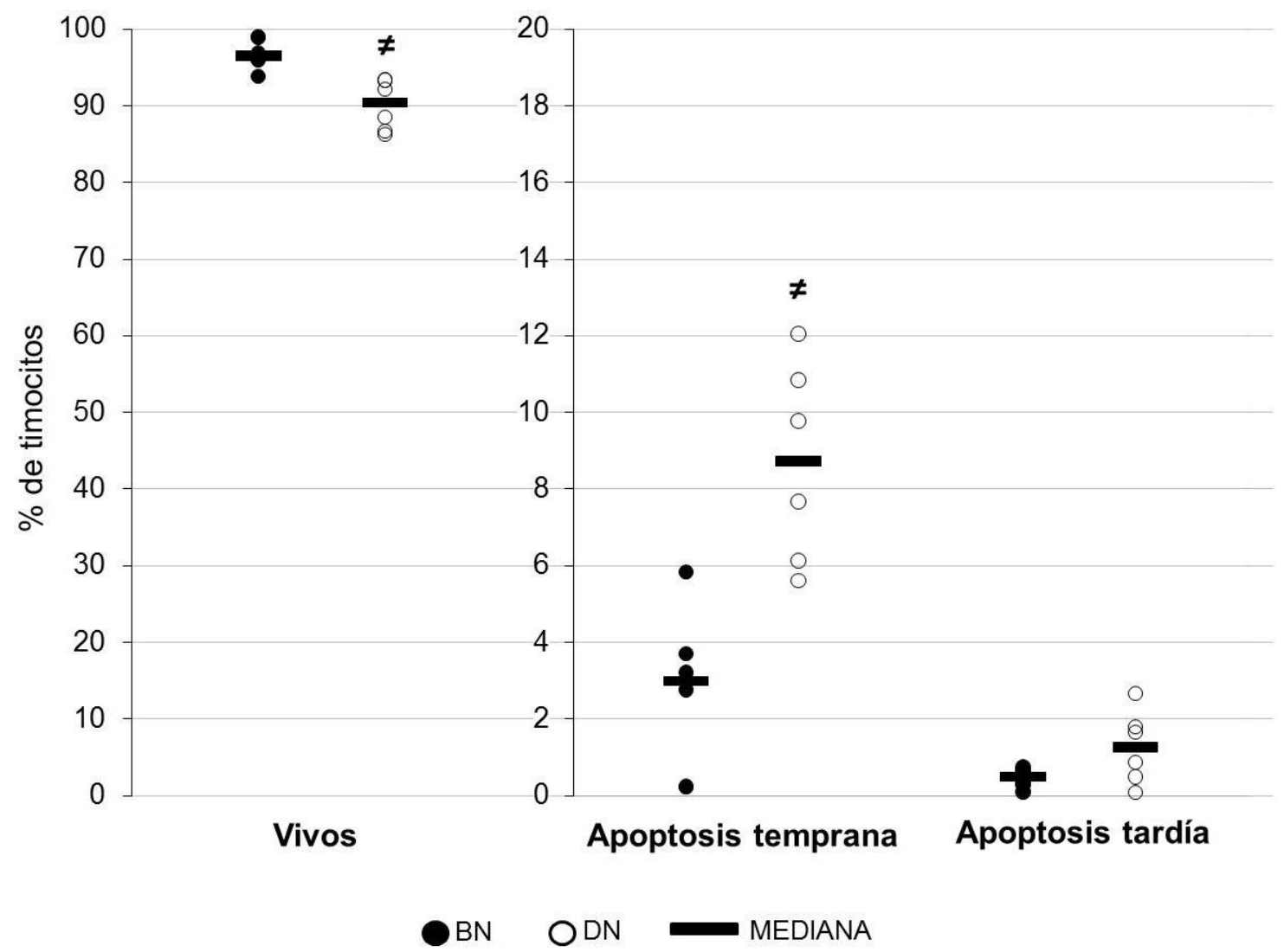

Figura 4. Análisis de apoptosis en timocitos CD4+CD8+ para los grupos BN y DN.

En el grupo DN se observó disminución de timocitos vivos, así como incremento en la apoptosis temprana, respecto al grupo $B N(n=6)$. $\neq p<0.05$ comparado con el grupo $B N$. 
En el grupo BN, la subpoblación CD4+ presentó $96.5 \pm 3.1 \%$ de timocitos vivos; 2.8 $\pm 3.0 \%$, en apoptosis temprana; $0.6 \pm 0.2 \%$, en apoptosis tardía (promedio $\pm \mathrm{DE}$ ). En el grupo DN, la subpoblación CD4+ presentó $85.5 \pm 4.9 \%$ de timocitos vivos; 12.4 $\pm 4.8 \%$, en apoptosis temprana; y $2.0 \pm 1.2 \%$, en apoptosis tardía.

En el grupo DN se observó disminución en la proporción de timocitos vivos, así como incremento en la apoptosis temprana y tardía, respecto al grupo BN [Figura 5].

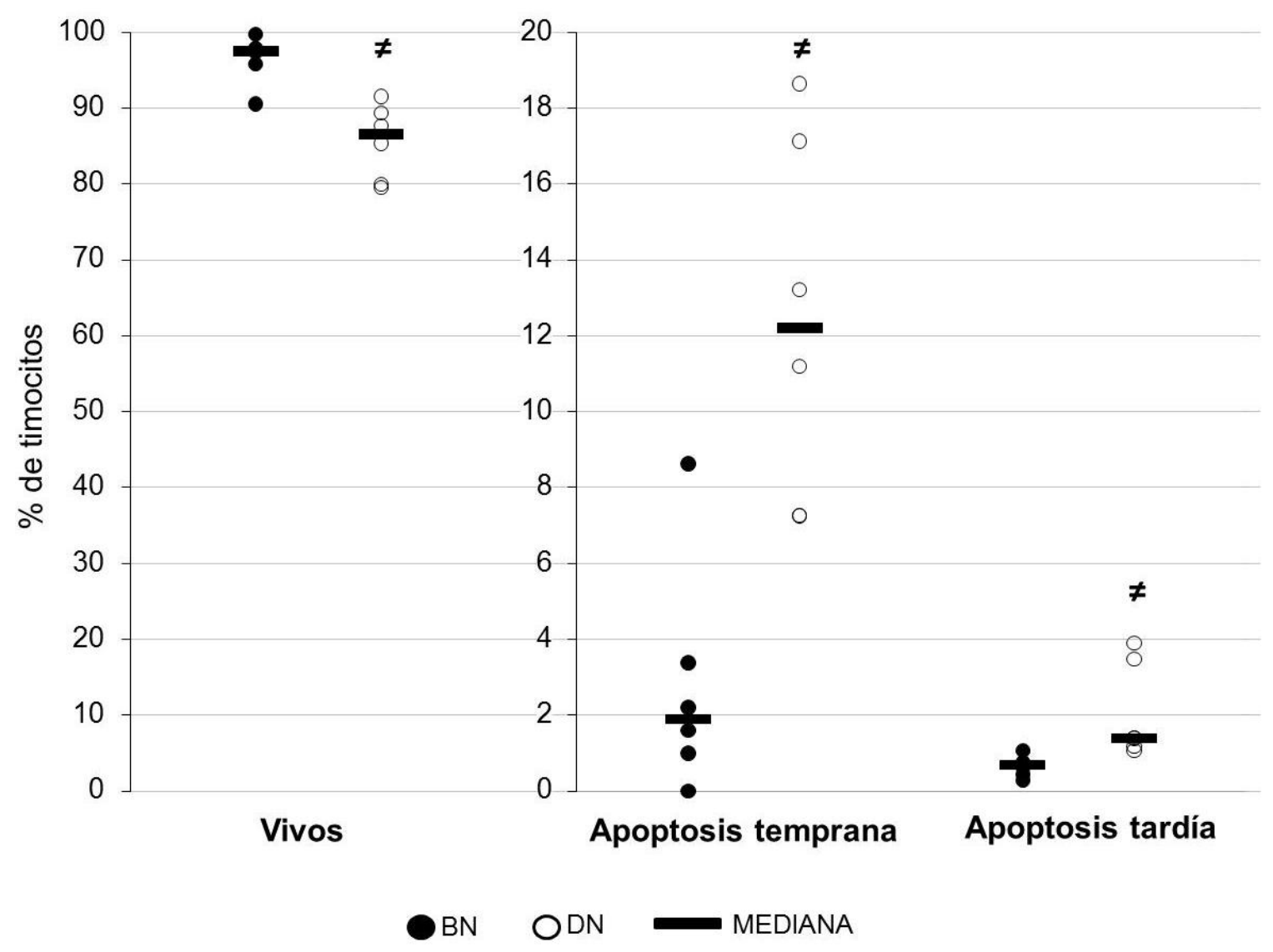

Figura 5. Análisis de apoptosis en timocitos CD4+ para los grupos BN y DN.

En el grupo DN se observó disminución en la proporción de timocitos vivos, así como incremento en la apoptosis temprana y tardía, respecto al grupo $B N(n=6) . \neq p<0.05$ comparado con el grupo BN. 
En el grupo BN, la subpoblación CD8+ presentó $88.0 \pm 2.7 \%$ de timocitos vivos; 3.4 $\pm 2.4 \%$, en apoptosis temprana; $8.0 \pm 2.7 \%$, en apoptosis tardía (promedio $\pm \mathrm{DE}$ ).

En el grupo DN, la subpoblación CD8+ presentó $75.3 \pm 9.9 \%$ de timocitos vivos; 7.7 $\pm 2.5 \%$ en apoptosis temprana; $16.6 \pm 9.6 \%$ en apoptosis tardía.

En el grupo DN se observó disminución en la proporción de timocitos vivos, así como incremento en la apoptosis temprana y tardía, respecto al grupo BN [Figura 6].

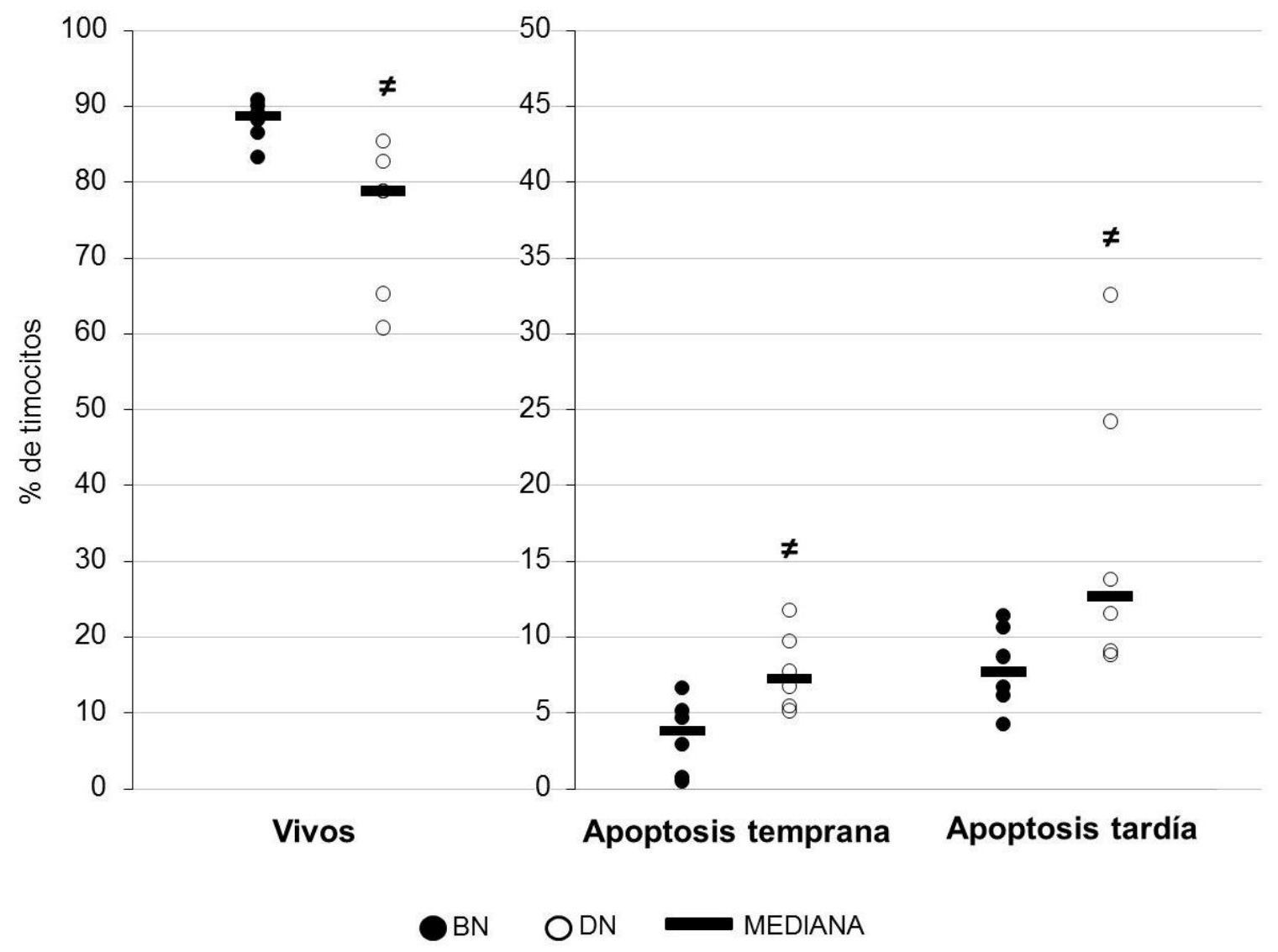

Figura 6. Análisis de apoptosis en timocitos CD8+ para los grupos BN y DN.

En el grupo DN se observó disminución de timocitos vivos e incremento de timocitos en apoptosis temprana y tardía, respecto al grupo BN $(n=6)$. $\neq p<0.05$ comparado con el grupo BN. 


\subsection{Análisis de la apoptosis en las fases del ciclo celular.}

Selección de la región de análisis.

El análisis del ciclo celular se realizó por cuantificación de ADN y la determinación de la apoptosis por la presencia de caspasas. La región de análisis se delimitó teniendo como parámetros a FL2-W contra FL2-A [llustración 8].
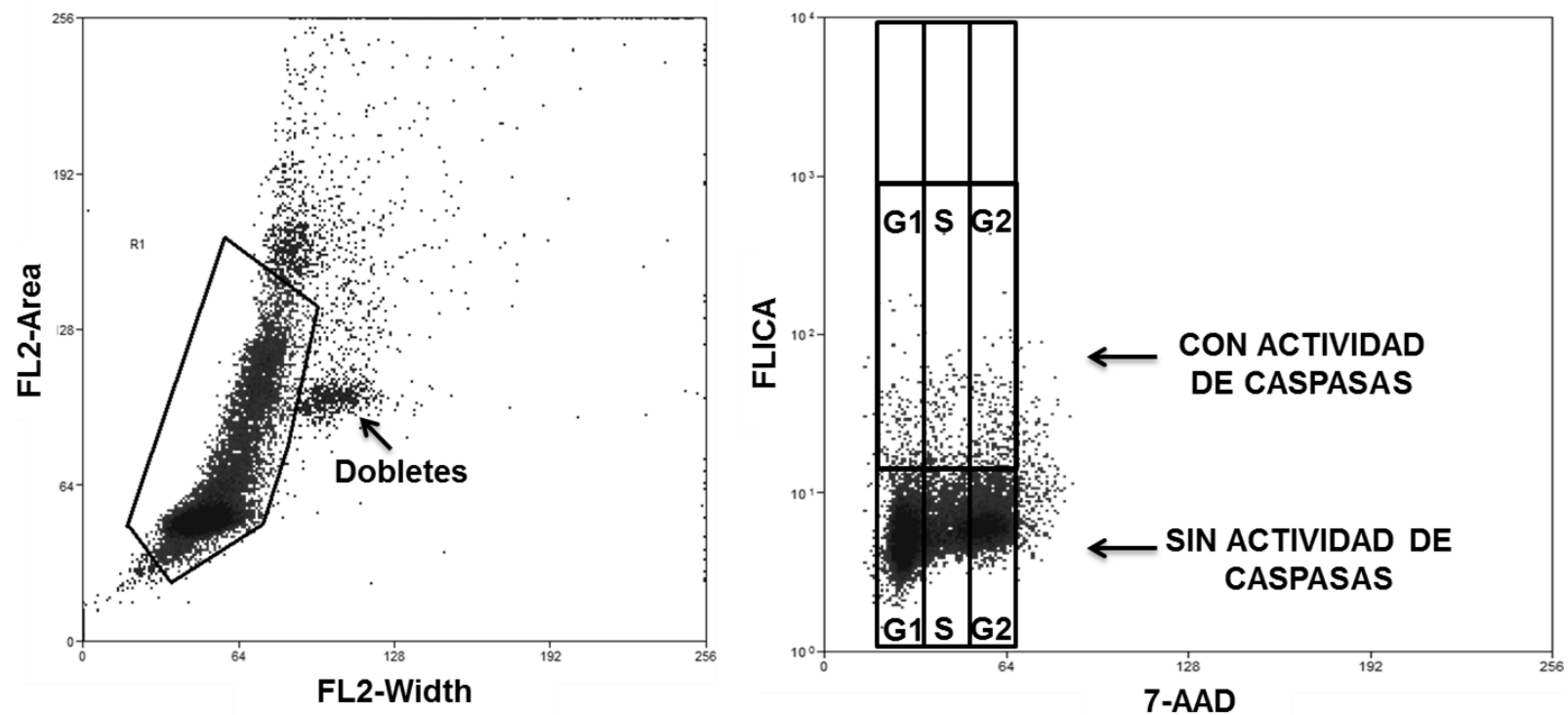

llustración 8. Identificación de timocitos en las fases del ciclo celular.

Izquierda: FL2-W es un parámetro que evalúa el tiempo de retardo en la recepción de la señal de un evento, útil para discriminar a los dobletes y excluirlos de la población células en G2/M. FL2-A permite determinar el contenido de ADN, mediante la fluorescencia del 7-AAD. La fluorescencia de 7-AAD es proporcional al contenido de ADN. Derecha: Regiones para identificar a los timocitos en cada una de las fases del ciclo celular: G0/G1, S y G2/M, determinadas por cuantificación de ADN. Los timocitos apoptóticos se distinguen por poseer fluorescencia para el reactivo de FLICA, indicando la presencia de caspasas. 
Se analizó la distribución de timocitos en cada fase del ciclo celular para seis muestras en cada uno de los cuatro grupos: BN, DN, BN DX y DN DX.

En el grupo BN se obtuvo $73.6 \pm 7.6 \%$ de timocitos en fase G0/G1; $17.4 \pm 4.0 \%$, en fase S; y $8.9 \pm 6.2 \%$, en fase G2/M (promedio $\pm D E$ ).

En el grupo DN se obtuvo $76.1 \pm 4.0 \%$ de timocitos en fase G0/G1; $16.4 \pm 4.5 \%$, en fase S; y $7.3 \pm 1.8 \%$, en fase G2/M.

En el grupo BN DX se obtuvo $57.6 \pm 6.8 \%$ de timocitos en fase G0/G1; $32.4 \pm 5.7 \%$, en fase S; y $9.8 \pm 4.5 \%$, en fase G2/M.

En el grupo DN DX se obtuvo $59.3 \pm 6.4 \%$ de timocitos en fase G0/G1; $30.1 \pm 6.3 \%$, en fase S; y $10.5 \pm 2.5 \%$, en fase $\mathrm{G} 2 / \mathrm{M}$.

No hubo diferencia estadísticamente significativa en la proporción de timocitos en cada fase del ciclo celular entre los grupos BN y DN. De forma similar que en los grupos no tratados, no hubo diferencia estadísticamente significativa en la proporción de timocitos en cada fase del ciclo celular entre BN DX y DN DX [Figura 7].

Al comparar los grupos tratados, respecto a los grupos sin tratamiento, se observó disminución en la proporción de timocitos en G0/G1 (disminución de 15.9 \% para BN DX; $16.8 \%$ para DN DX); incremento en S (incremento de $14.9 \%$ para BN DX; 13.7 \% para DN DX); así como en G2/M (incremento de $3.1 \%$ para DN DX); sin ser significativamente diferente en G2/M para BN y BN DX (incremento de $0.9 \%$ para BN DX;) [Figura 7]. 


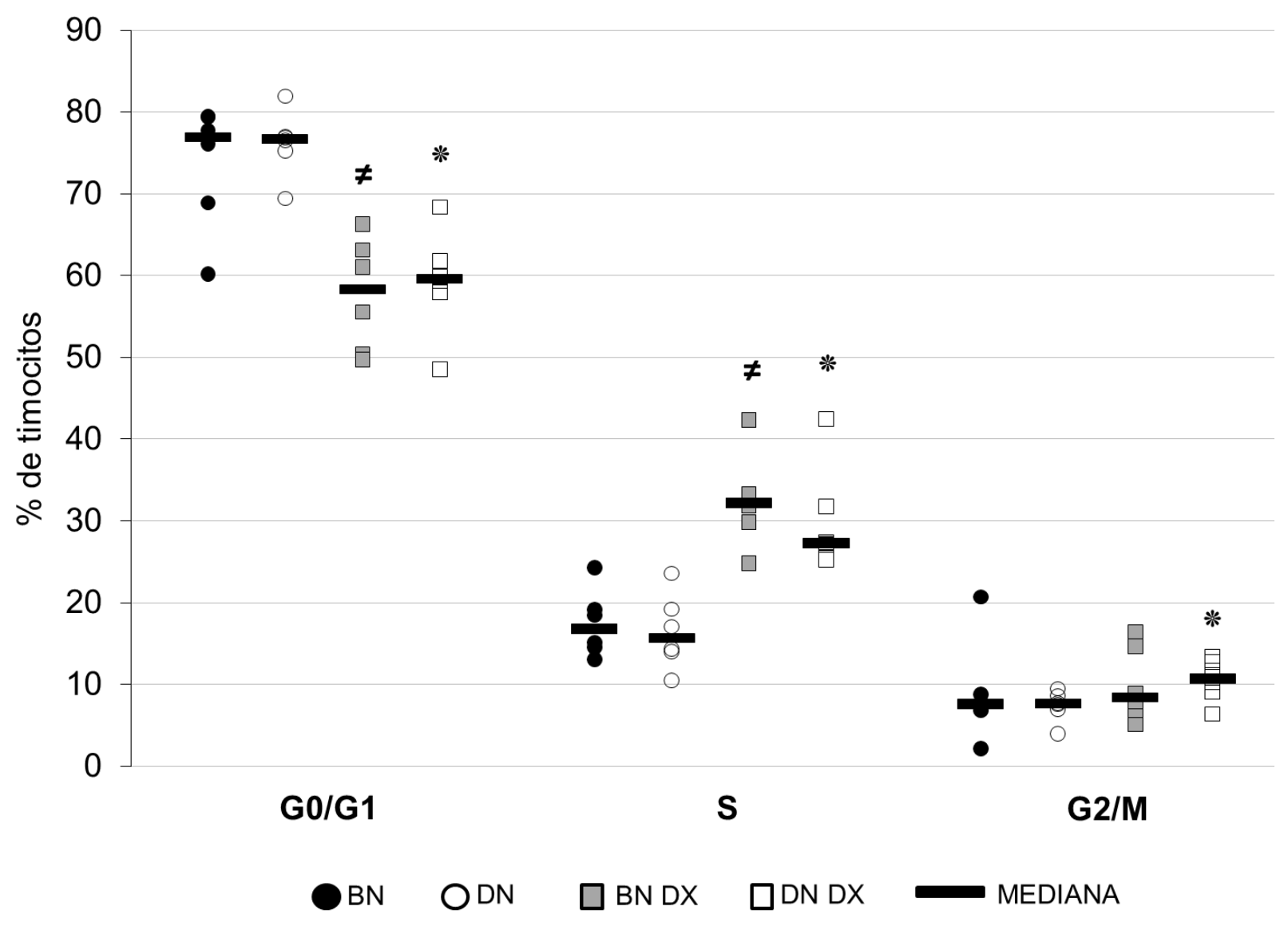

Figura 7. Análisis de timocitos en cada fase del ciclo celular.

No hubo diferencia estadísticamente significativa en la proporción de timocitos en cada fase del ciclo celular entre los grupos BN y DN. No hubo diferencia estadísticamente significativa en la proporción de timocitos en cada fase del ciclo celular entre los grupos BN DX y DN DX $(n=6).) . \neq p<0.05$ comparado con el grupo BN; * $p<0.05$ comparado con el grupo DN.

Posteriormente se analizaron únicamente a los timocitos positivos a caspasas, en cada fase del ciclo celular. Se graficó la fluorescencia de 7-AAD (FL3), dada por el contenido de ADN contra la fluorescencia de FLICA poli-caspasas (FL1) [llustración 8]. 
El análisis se realizó para seis muestras en cada uno de los cuatro grupos: BN, DN, BN DX y DN DX. Los resultados expresan porcentajes a partir de la población de timocitos positivos a caspasas.

En el grupo BN se obtuvo $40.9 \pm 12.1 \%$ de timocitos apoptóticos en G0/G1; $37.8 \pm$ $11.0 \%$, en fase $S$ y $21.2 \pm 8.9 \%$, en fase G2/M (promedio $\pm D E$ ).

En el grupo DN se obtuvo $56.7 \pm 7.8 \%$ de timocitos apoptóticos en G0/G1; $24.3 \pm 4.3$ $\%$, en fase S y $18.9 \pm 7.0 \%$, en fase G2/M [Figura 8].

Al comparar al grupo DN respecto al grupo BN, se observó incremento en la proporción de timocitos en apoptosis en G0/G1 y disminución en S.

En el grupo BN DX se obtuvo $42.3 \pm 9.8 \%$ de timocitos apoptóticos en G0/G1; $46.0 \pm$ $8.7 \%$, en fase $S$ y $11.5 \pm 4.4 \%$, en fase $\mathrm{G} 2 / \mathrm{M}$.

En el grupo DN DX se obtuvo $58.3 \pm 6.5 \%$ de timocitos apoptóticos en G0/G1; $27.5 \pm$ $6.8 \%$, en fase S y $14.4 \pm 4.9 \%$, en fase G2/M.

De forma similar que en los grupos no tratados, al comparar el grupo DN DX respecto al grupo BN DX, se observó incremento en la proporción de timocitos apoptóticos en G0/G1 y disminución en S [Figura 8].

No se observó diferencia en la proporción de timocitos apoptóticos en las fases G0/G1 y $S$ en los grupos tratados, en comparación a los grupos sin tratamiento. Únicamente se observó disminución de la proporción de timocitos apoptóticos en G2/M en el grupo BN DX respecto al grupo BN; así como tendencia a la disminución en la proporción de timocitos apoptóticos en G2/M en el grupo DN DX respecto al grupo DN. 


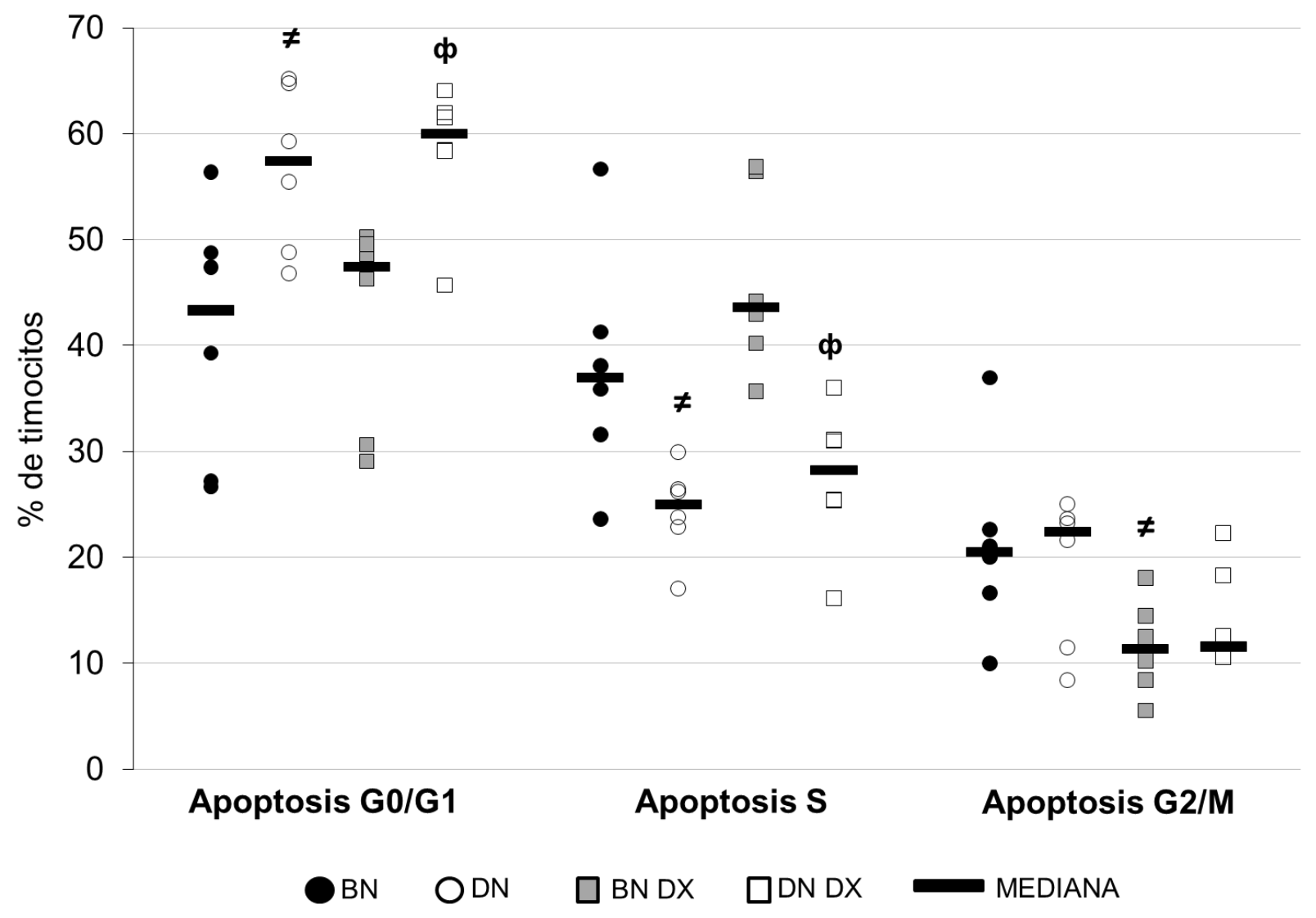

Figura 8. Análisis de apoptosis de timocitos en las fases del ciclo celular.

Se observó incremento en la proporción de timocitos con caspasas en G0/G1 y disminución en $\mathrm{S}$, en el grupo DN respecto al grupo BN. Se observó incremento en la proporción de timocitos con caspasas en G0/G1 y disminución en S, en el grupo DN DX respecto al grupo BN DX(n=6). $\neq p<0.05$ comparado con el grupo BN; $\phi p<0.05$ comparado con el grupo BN DX. 


\subsection{Análisis de la apoptosis temprana en timocitos, mediante la identificación de las caspasas iniciadoras de apoptosis -8 y -9 .}

Selección de la región de análisis.

Posterior a la identificación de la población de timocitos, se identificaron a los timocitos vivos, en apoptosis temprana, tardía y necrosis [llustración 9]. Este análisis se realizó para seis muestras de los grupos BN y DN.

Los valores obtenidos se expresan en porcentajes respecto a la población total de timocitos. La apoptosis temprana se determinó mediante el análisis de los timocitos positivos a FLICA -8 o -9 .
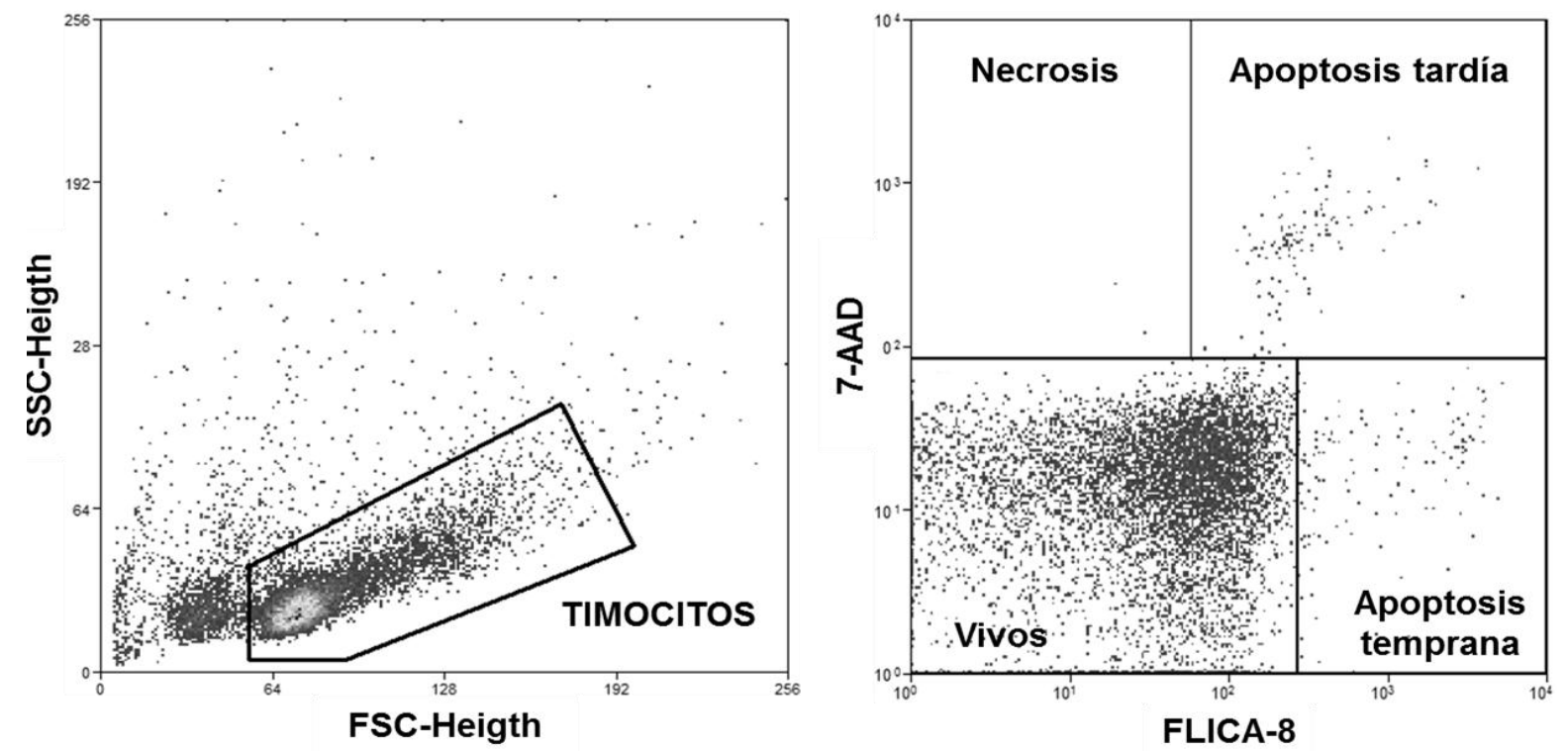

FLICA-8

Ilustración 9. Gráficas para la identificación de apoptosis temprana en timocitos.

Izquierda: Gráfica para la identificación de la población total de timocitos en una muestra de una rata DN. Derecha: Gráfica para la identificación de timocitos vivos, en apoptosis temprana, tardía y necrosis, obtenida la graficar la fluorescencia de FLICA-8 o -9 contra 7AAD. 
Al analizar los timocitos positivos a caspasa-8 en el grupo BN, se obtuvo $2.7 \pm 0.7 \%$ de timocitos en apoptosis temprana. En el análisis contra caspasa-9 se obtuvo $2.6 \pm$ $0.3 \%$ de timocitos en apoptosis temprana (promedio $\pm D E$ ).

En el análisis de los timocitos positivos a caspasa-8 en el grupo DN, se obtuvo $6.5 \%$ $\pm 1.7 \%$ de timocitos en apoptosis temprana. Contra caspasa-9 se obtuvo $8.4 \pm 2.6 \%$ de timocitos en apoptosis temprana.

Al comparar el grupo DN respecto al grupo BN, se observó incremento significativo en la proporción de timocitos en apoptosis temprana, tanto para el análisis por caspasa-8 como por caspasa-9 [Figura 9]. Posterior a este análisis se comparó la proporción de timocitos en apoptosis temprana positivos a caspasa-8 contra los positivos a caspasa-9 en cada grupo.

Al comparar la proporción de timocitos en apoptosis temprana analizados por caspasa-8 contra los analizados por caspasa -9 en el grupo BN, no hubo diferencia; mientras que en la misma comparación hecha para el grupo DN, se observó tendencia al incremento de la proporción de timocitos con caspasa-9 [Figura 9].

No se observó diferencia entre la proporción de timocitos en apoptosis tardía analizados por caspasa-8 contra los timocitos analizados por caspas-9 en BN, ni en DN. 


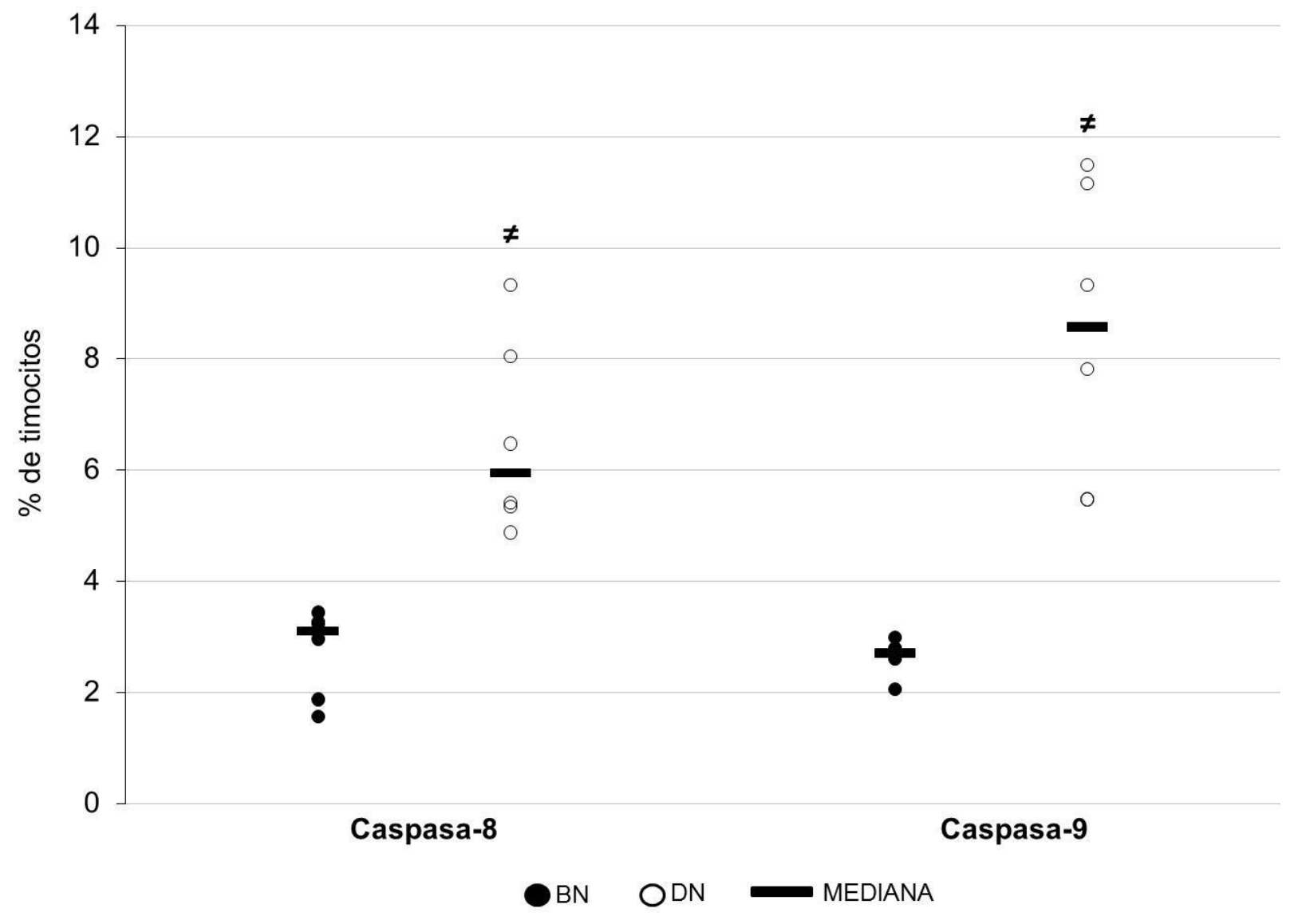

Figura 9. Análisis de timocitos en apoptosis temprana.

En el análisis de la apoptosis mediante la presencia de caspasas -8 o -9 , se observó incremento en la proporción de timocitos en apoptosis temprana en el grupo DN, respecto al grupo BN, en ambos casos. No se observó diferencia entre la proporción de timocitos en apoptosis temprana positivos a caspasa-8 contra los analizados por caspasa-9 para el grupo BN; mientras que en el grupo DN, se observó tendencia al incremento de la proporción de timocitos en apoptosis temprana analizados por caspasa-9, respecto a los analizados por caspasa-8 $(n=6) . \neq p<0.05$ comparado con el grupo BN. 
7.6 Análisis de la apoptosis temprana en subpoblaciones de timocitos, mediante la presencia de las caspasas iniciadoras -8 y -9 .

Selección de la región de análisis.

Posterior a la identificación de la población de timocitos, se delimitaron a las cuatro subpoblaciones analizadas: CD4-CD8-, CD4+CD8+, CD4+ y CD8+. Después de identificar a cada subpoblación, se analizaron los timocitos en apoptosis temprana, mediante la presencia de caspasas -8 o $\quad-9$ en cada una de ellas de forma independiente, como se observa en la ilustración 10.

Los resultados muestran el porcentaje de timocitos en apoptosis temprana, respecto al total de timocitos en cada subpoblación. 

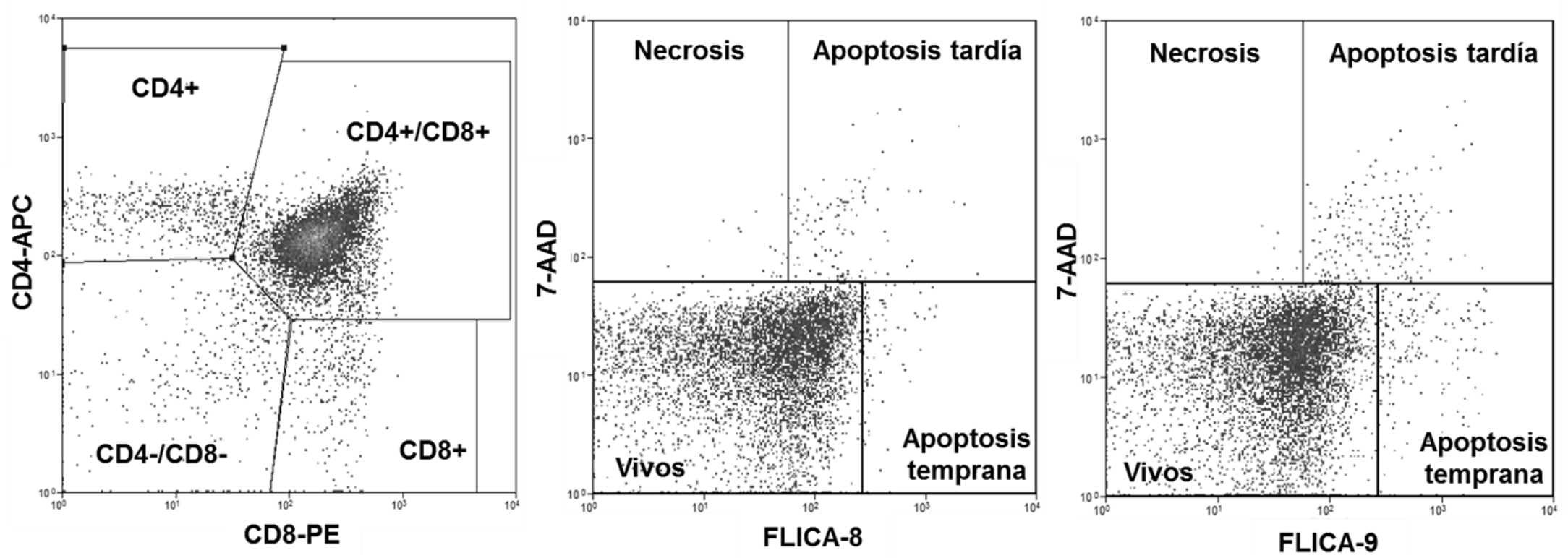

Ilustración 10. Análisis de apoptosis temprana en las subpoblaciones de timocitos.

Izquierda: Las subpoblaciones de timocitos CD4-CD8-, CD4+CD8+, CD4+ y CD8+ se identificaron al graficar la señal recibida por CD8-PE contra CD4-APC. Centro y derecha: Análisis de la apoptosis temprana en la subpoblación CD4+CD8+en una muestra de rata DN, mediante la detección de caspasa-8 y caspasa-9. A partir de cada subpoblación de timocitos, se graficó la señal recibida por FLICA-8 o -9 contra 7-AAD para identificar a los timocitos en apoptosis temprana. 


\section{Subpoblación CD4-CD8-}

En el análisis de los timocitos positivos a caspasa-8 en el grupo BN, se obtuvo $2.8 \pm$ $1.2 \%$ de timocitos en apoptosis temprana (promedio $\pm \mathrm{DE}$ ). Mediante el análisis contra caspasa-9 se obtuvo $3.0 \pm 1.3 \%$ de timocitos en apoptosis temprana.

En el análisis de los timocitos positivos a caspasa-8 en el grupo DN, se obtuvo $5.9 \pm$ $1.1 \%$ de timocitos en apoptosis temprana. Mediante el análisis contra caspasa-9 se obtuvo $10.2 \pm 3.6 \%$ de timocitos en apoptosis temprana.

En el grupo DN, se observó incremento en la proporción de timocitos en apoptosis temprana respecto al grupo $\mathrm{BN}$, tanto por el análisis por caspasa-8 como en el análisis por caspasa-9 [Figura 10 y 11].

En el grupo BN, al comparar a los timocitos CD4-CD8- en apoptosis temprana analizados por caspasa-8 contra los analizados por caspasa-9, no hubo diferencia. En el grupo DN se observó incremento de la proporción de timocitos con caspasa-9, respecto a los analizados por caspasa-8 [Figura 12].

\section{Subpoblación $C D 4+C D 8+$}

En el análisis de los timocitos positivos a caspasa-8 el grupo BN, se obtuvo $0.7 \pm 0.5$ $\%$ de timocitos en apoptosis temprana (promedio $\pm \mathrm{DE}$ ). Mediante el análisis contra caspasa- 9 se obtuvo $0.7 \pm 0.5 \%$ de timocitos en apoptosis temprana.

En el análisis de los timocitos positivos a caspasa-8 en el grupo DN, se obtuvo $3.0 \pm$ $0.8 \%$ de timocitos en apoptosis temprana. Mediante el análisis contra caspasa-9 se obtuvo $5.1 \pm 1.7 \%$ de timocitos en apoptosis temprana. 
En el grupo DN, se observó incremento en la proporción de timocitos en apoptosis temprana respecto al grupo BN, tanto por el análisis por caspasa-8 como en caspasa-9 [Figura 10 y 11$]$.

En el grupo BN, al comparar la proporción de los timocitos CD4+CD8+ en apoptosis temprana analizados por caspasa-8 contra los analizados por caspasa-9, no hubo diferencia. En el grupo DN se observó incremento de timocitos con caspasa-9, respecto a los analizados por caspasa-8 [Figura 12].

\section{Subpoblación CD4+}

En el análisis de los timocitos positivos a caspasa-8 el grupo BN, se observó $18.3 \pm$ $6.2 \%$ de timocitos en apoptosis temprana (promedio $\pm \mathrm{DE}$ ). Mediante el análisis contra caspasa-9 se obtuvo $14.1 \pm 1.3 \%$ de timocitos en apoptosis temprana.

En el análisis de los timocitos positivos a caspasa-8 en el grupo DN, se obtuvo 27.6 $\pm 6.8 \%$ de timocitos en apoptosis temprana. Mediante el análisis contra caspasa-9 se obtuvo $26.0 \pm 13.3 \%$ de timocitos en apoptosis temprana.

En el grupo DN, se observó incremento en la proporción de timocitos en apoptosis temprana, respecto al grupo $\mathrm{BN}$, tanto por el análisis por caspasa-8 como en caspasa-9 [Figura 10 y 11$]$.

Al comparar la proporción de los timocitos CD4+ en apoptosis temprana analizados por caspasa-8 contra los analizados por caspasa-9, no hubo diferencia en el grupo BN, ni en el grupo DN [Figura 12]. 


\section{Subpoblación CD8+}

En el análisis de los timocitos positivos a caspasa-8 el grupo BN, se obtuvo $0.7 \pm 0.6$ $\%$ de timocitos en apoptosis temprana (promedio $\pm \mathrm{DE}$ ). Mediante el análisis contra caspasa- 9 se obtuvo $0.7 \pm 0.6 \%$ de timocitos en apoptosis temprana.

En el análisis de los timocitos positivos a caspasa-8 en el grupo DN, se obtuvo $6.2 \pm$ $2.8 \%$ de timocitos en apoptosis temprana. Mediante el análisis por caspasa-9 se obtuvo $12.8 \pm 5.3 \%$ de timocitos en apoptosis temprana.

En el grupo DN, se observó incremento en la proporción de timocitos en apoptosis temprana, respecto al grupo $\mathrm{BN}$; tanto por el análisis por caspasa-8 como en caspasa-9 [Figura 10 y 11$]$.

En el grupo BN, al comparar la proporción de los timocitos CD8+ en apoptosis temprana analizados por caspasa-8 contra los analizados por caspasa-9, no hubo diferencia. En el grupo DN, se observó incremento en la proporción de timocitos positivos a caspasa-9, respecto a los positivos a caspasa-8 [Figura 12]. 


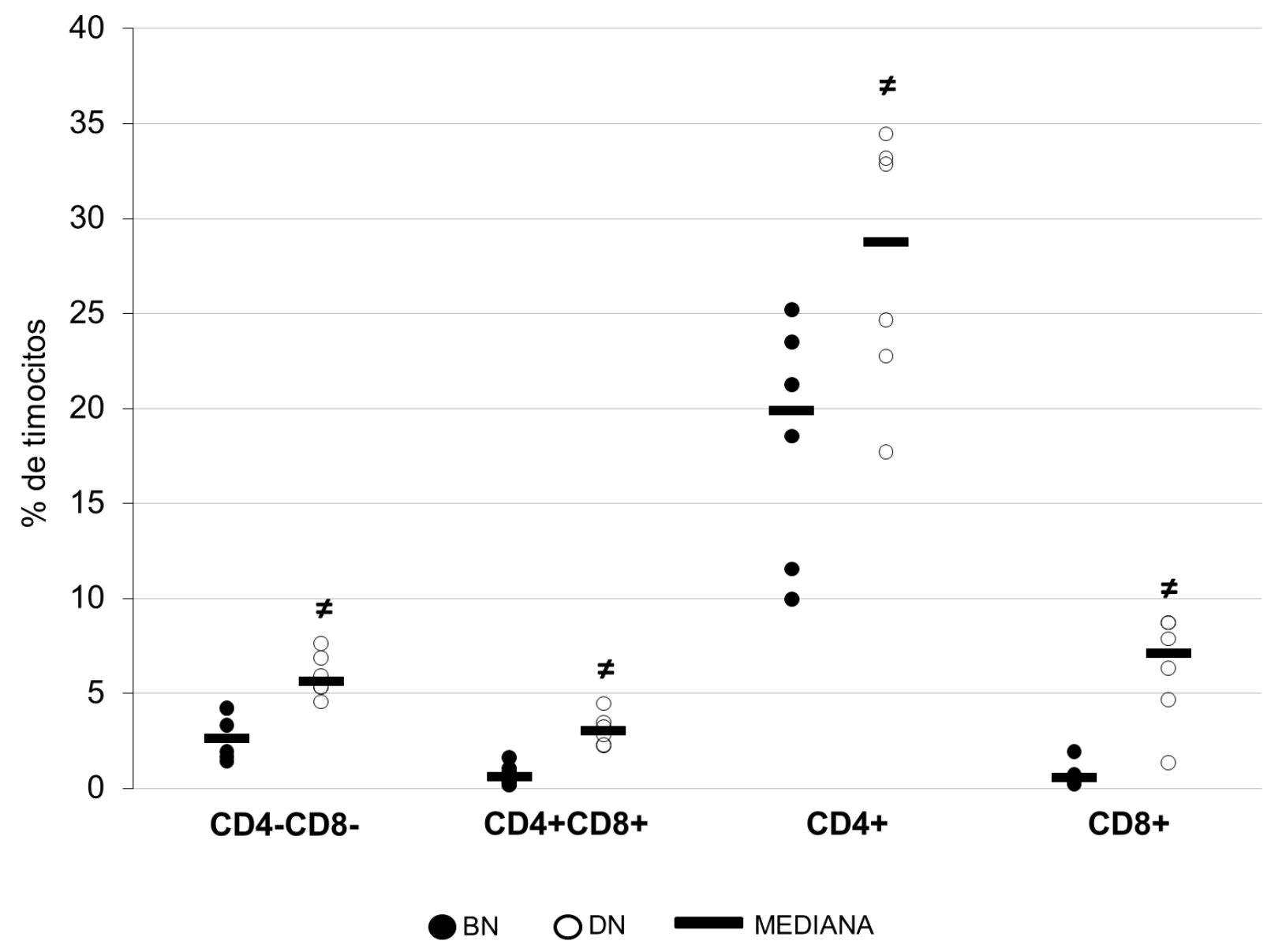

Figura 10. Apoptosis temprana analizada mediante la presencia de caspasa-8.

Se muestra la proporción de timocitos en apoptosis temprana correspondiente al analizar separadamente a cada subpoblación, mediante la presencia de caspasa-8. En el grupo DN, se observó incremento en la proporción de timocitos en apoptosis temprana en cada una de las subpoblaciones, respecto al grupo $\mathrm{BN}(n=6)$. $\neq p<0.05$ comparado con el grupo $\mathrm{BN}$. 


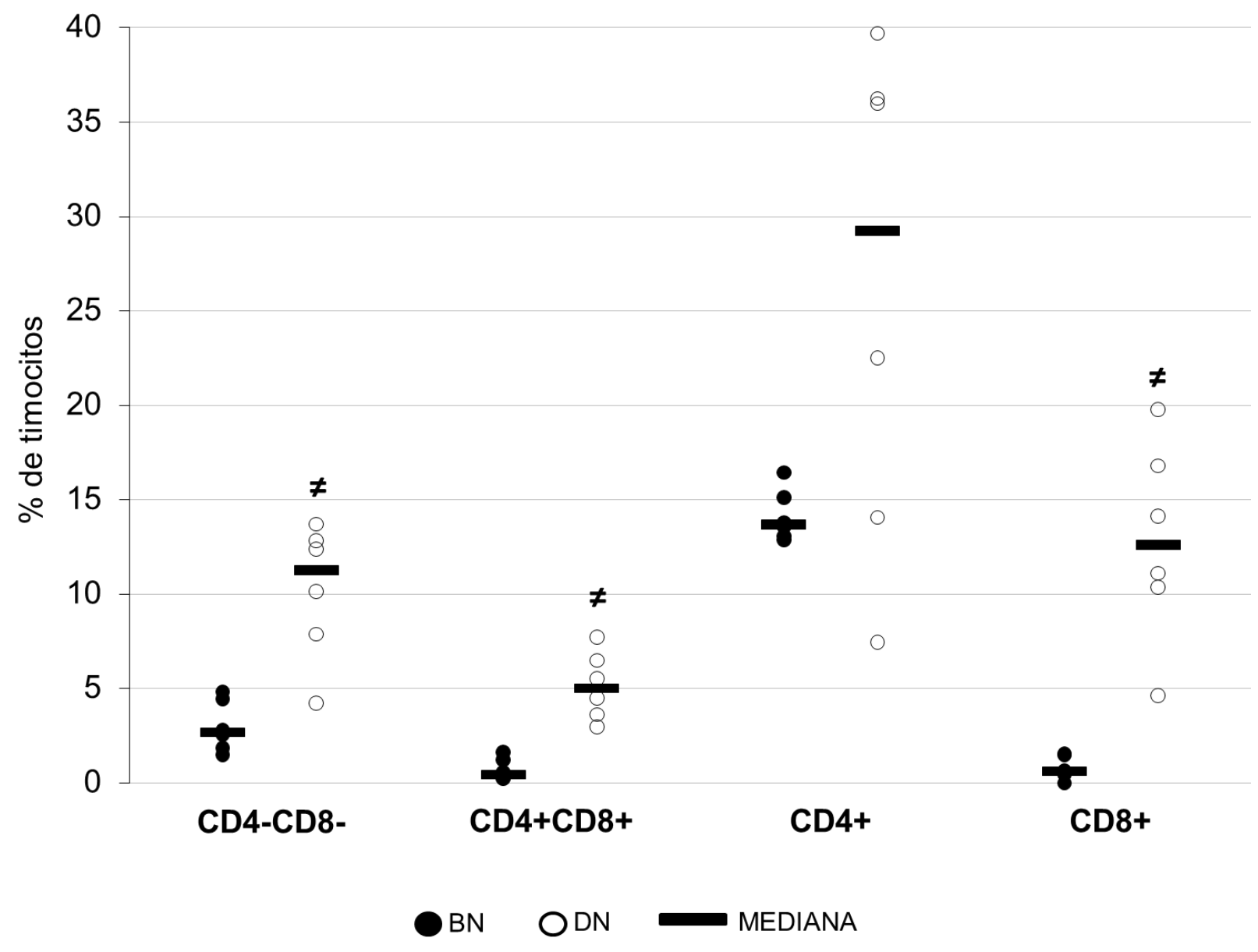

Figura 11. Apoptosis temprana analizada mediante la presencia de caspasa-9.

Se muestra la proporción de timocitos en apoptosis temprana correspondiente al analizar separadamente a cada subpoblación, mediante la presencia de caspasa-9. En el grupo DN, se observó incremento en la proporción de timocitos en apoptosis temprana en CD4-CD8-, $\mathrm{CD} 4+\mathrm{CD} 8+$ y $C D 8+$, respecto al grupo $\mathrm{BN}(\mathrm{n}=6) . \neq p<0.05$ comparado con $\mathrm{BN}$ el grupo. 


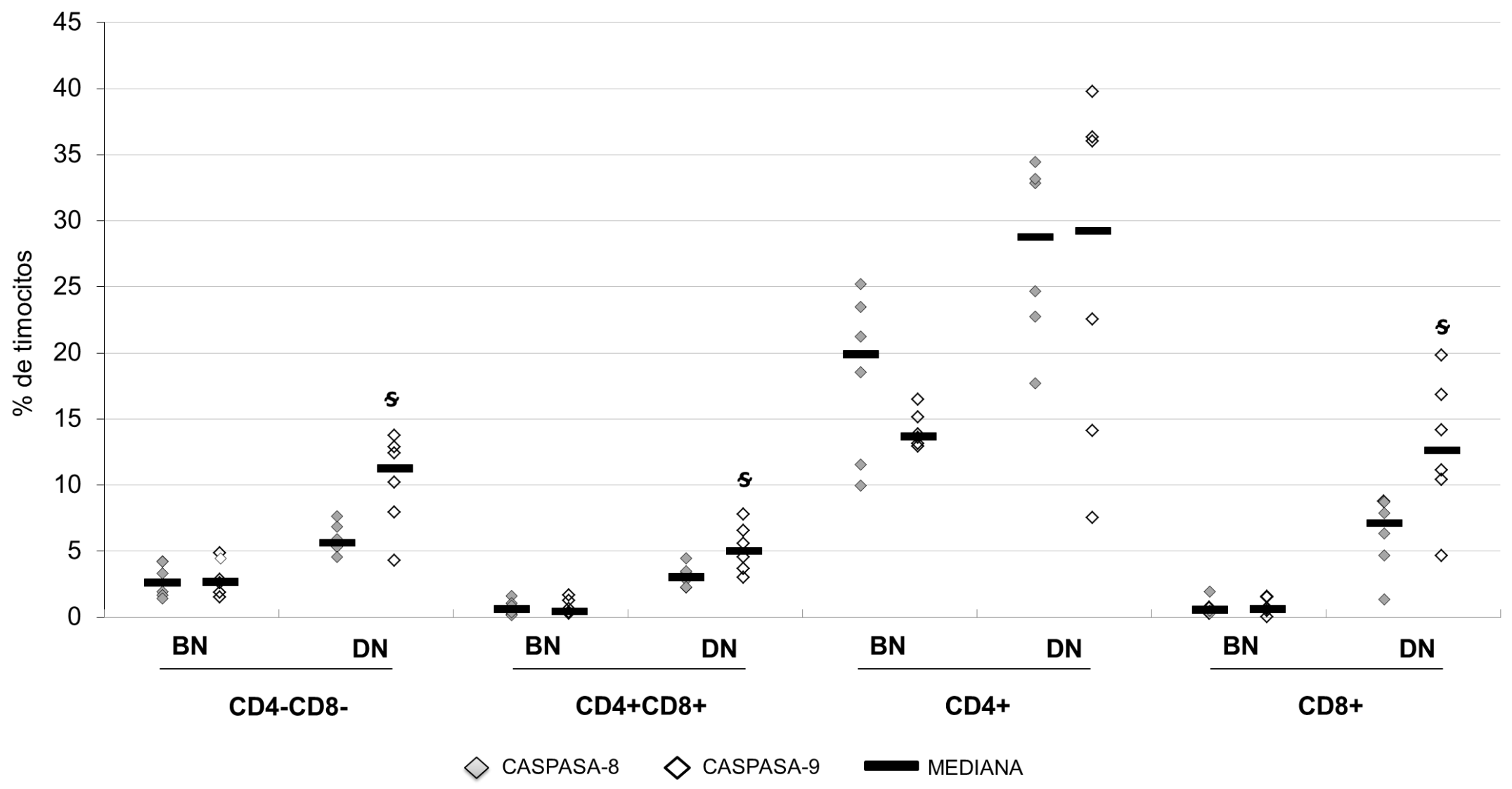

Figura 12. Timocitos en apoptosis temprana en cada subpoblación, para los grupos BN y DN.

Se muestra la proporción de timocitos en apoptosis temprana correspondiente al analizar separadamente a cada subpoblación.

Al comparar la proporción de timocitos positivos a caspasa-8 contra los timocitos positivos a caspasa-9, no se observó diferencia en alguna de las subpoblaciones en el grupo BN, mientras que en el grupo DN se observó incremento en la proporción de timocitos en apoptosis temprana en CD4-CD8-, CD4+CD8+ y CD8+ $(n=6)$. $s$ p<0.05 comparado con caspasa-8. 


\section{DISCUSIÓN.}

El presente trabajo tuvo la finalidad de establecer la relación entre el incremento de la apoptosis en timocitos observada en desnutrición (Ortiz y cols., 2009) y las vías que la desencadenan, para poder establecer premisas que contribuyan a explicar el efecto de la desnutrición en el sistema inmunológico y su relación con la inmunodeficiencia.

\subsection{Datos de las muestras.}

En la desnutrición de tercer grado o grave, la pérdida de peso del organismo es superior al 40 \% (Gómez, 1946) y es en donde se observan los efectos más deletéreos. Los clasificados en el tercer grado de desnutrición son los que poseen un riesgo de mortalidad más elevado (Prudhon, 2002).

Como se ha reportado en trabajos previos, el timo se muestra afectado en la desnutrición (Purtiloy Connor, 1975), en este estudio se demostró que en ratas desnutridas, el timo posee menor tamaño y disminución de timocitos; sin embargo no se alteró la proporción celular en función del peso del órgano, respecto en ratas bien nutridas, esto indica que la densidad celular se mantiene.

El tratamiento con dexametasona influyó negativamente en el peso del timo y disminuyó la proporción celular en ambos grupos tratados, respecto a sus grupos sin tratamiento, lo que confirma que la dexametasona afecta negativamente a los timocitos (Boumpas y cols., 1993; Ortiz y cols., 2009). Por otra parte, al analizar a 
ambos grupos con tratamiento no se observó diferencia en el peso de los timos, así como en la cuenta celular y en consecuencia la proporción celular no fue diferente en los grupos tratados, lo que demuestra que la dexametasona afecta negativamente al timo de forma independientemente de la condición nutricional.

\subsection{Apoptosis en timocitos.}

Las caspasas se han observado en diversos tipos celulares y su pérdida evita la muerte celular programada por lo que su presencia se ha definido como uno de los biomarcadores del proceso apoptótico (Thornberry y Molineaux, 1995).

Los timocitos vivos disminuyeron en el grupo DN y se observó incremento de apoptosis temprana y tardía, de acuerdo a estudios previos, donde se observó incremento tanto en la apoptosis temprana como en la tardía, determinada con anexina-V/yoduro de propidio (Ortiz y cols., 2009). Los resultados en este trabajo no muestran diferencia en la proporción de timocitos necróticos entre los grupos BN y DN, se confirma que el aumento de muerte en timocitos se da por apoptosis y no por necrosis.

El tratamiento con dexametasona disminuyó el porcentaje de timocitos vivos e incrementó la apoptosis, en comparación con los grupos sin tratamiento. Estos resultados concuerdan con estudios de apoptosis inducida por glucocorticoides en timocitos, en donde la dexametasona incrementó la apoptosis en las diferentes poblaciones de timocitos (Ortiz y cols., 2001), siendo los linfocitos CD4+CD8+ los más afectados por la apoptosis (Cohen, 1992). 
Adicionalmente, se observó una tendencia al incremento de la necrosis, lo que puede sugerir una disminución de la resistencia en los timocitos a la manipulación, a consecuencia del tratamiento con dexametasona.

\subsection{Apoptosis temprana y tardía en subpoblaciones de timocitos.}

La maduración de los timocitos ocurre en regiones tímicas especializadas y está dado por la expresión de diferentes fenotipos, en consecuencia el timo posee poblaciones heterogéneas de timocitos. Este fenotipo se define por la expresión del complejo de receptor de células T (TCR) y los correceptores CD4 y/o CD8, encontrando en el timo cuatro subpoblaciones principales: CD4-CD8-, CD4+CD8+, CD4+, y CD8+ (Chen, 2004).

Nuestros datos concuerdan con estudios previos, en donde se han demostrado que la desnutrición afecta la proporción de subpoblaciones de timocitos (Ortiz y cols., 2009), pues en este estudio se observó incremento de timocitos inmaduros: CD4CD8-, CD4+CD8+ y disminución de CD4+ y CD8+. Esto puede sugerir una alteración en el proceso de maduración/diferenciación en los timocitos CD4-CD8- y CD4+CD8+, posiblemente relacionado a la falta de estímulos adecuados (Savino, 2002) intra o extracelulares que favorezcan su pronta maduración, que podría prolongar el proceso de maduración hacia timocitos CD4+ y CD8+ e influir en su disminución.

En estudios previos, utilizando el ensayo de TUNEL y anexina V/yoduro de propidio, se observó incremento de apoptosis en timocitos CD4-CD8-, CD4+ y CD8+ en ratas desnutridas (Ortiz y cols., 2009). Al analizar la apoptosis por actividad de caspasas 
se observó que las subpoblaciones más afectadas por apoptosis tardía fueron las CD4-CD8- y CD8+, para los grupos BN y DN; siendo significativamente mayor en DN tanto en apoptosis temprana como tardía, respaldando a los estudios previamente publicados por Ortiz y cols., en 2009.

Se observó incremento de la proporción de timocitos en apoptosis temprana en la subpoblación CD4+ y CD4+CD8+ para el grupo DN respecto al grupo BN.

Los presentes datos apoyan que la desnutrición tiene efecto, principalmente, sobre el incremento de apoptosis en los timocitos CD4-CD8-, CD4+ y CD8+.

La disminución en la proporción de timocitos CD4+ y CD8+ podría estar relacionada con el incremento en la proporción de timocitos apoptóticos en CD4-CD8- y CD4+CD8+. La disminución en la proporción de timocitos CD4+ y CD8+ y el incremento de apoptosis en estas subpoblaciones en ratas DN, sugiere una disminución de linfocitos T funcionales en la periferia, lo que podría relacionarse con el incremento la susceptibilidad a infecciones en desnutrición (Tamayo, 1997).

\subsection{Apoptosis en las fases del ciclo celular.}

Se ha planteado que la apoptosis en timocitos se encuentra ligada a la expresión de proteínas involucradas en el ciclo celular, contribuyendo a su sensibilidad a la apoptosis (Xue y cols., 2008).

Adicionalmente, en la desnutrición el microambiente tímico presenta alteraciones, debido a que las células epiteliales tímicas presentan cambios morfológicos y 
disminución de la producción de hormonas: timopoietina, factor tímico sérico, timosina y factor humoral tímico (Chandra, 1979; Savino, 2002).

Faltan estudios que investiguen la relación entre el efecto de las hormonas tímicas, la progresión del ciclo celular y la apoptosis en timocitos. Sin embargo, es probable que la alteración en las células epiteliales y con ello, la producción de hormonas tímicas, estén involucradas en el incremento de apoptosis en timocitos de individuos desnutridos y que ésta se de en alguna fase específica del ciclo celular.

Al analizar la distribución de células en cada fase del ciclo celular, no se observó diferencia entre los grupos BN y DN, lo que sugiere que la desnutrición no afecta a la distribución de timocitos en cada fase del ciclo celular.

En ambos grupos tratados con dexametasona se observó disminución en la proporción de timocitos encontrados en G0/G1, incremento en la fase $S$, y tendencia a incrementar en G2/M, en comparación a sus respectivos grupos testigos. Probablemente se deba a la disminución de timocitos en fase G0/G1 por apoptosis, debido al tratamiento, lo que muestra un aparente incremento de la distribución de timocitos en las fases $S$ y $\mathrm{G} 2 / \mathrm{M}$.

Se han realizado estudios que muestran que la apoptosis espontánea en timocitos ocurre en todas las fases del ciclo celular (Pellicciari y cols., 1996), lo cual pudo corroborarse al relacionar la fase del ciclo celular con la actividad de caspasas. En los cuatro grupos estudiados se observó actividad de caspasas en las fases G0/G1, S y G2/M, lo que sugiere que la apoptosis se efectúa en cada una de ellas. 
En BN los timocitos apoptóticos se distribuyen principalmente en las fases G0/G1 y $\mathrm{S}$, contrariamente a estudios previos en donde se observaron frecuencias relativas similares de apoptosis en G0/G1, S y G2/M (Pellicciari y cols., 1996).

En el grupo DN los timocitos apoptóticos se distribuyen principalmente en la fase G0/G1. La desnutrición establece una relación entre la fase del ciclo celular y la muerte de los timocitos. Probablemente la apoptosis en G0/G1 se vea favorecida por su tiempo de duración de esta fase o bien por sus características propias de expresión de moléculas involucradas en esta fase del ciclo celular.

Considerando que G0/G1 es la fase más prolongada del ciclo celular, la probabilidad de que la apoptosis de los timocitos se desencadene en esta fase es alta.

En el grupo BN DX los timocitos apoptóticos se distribuyen principalmente en las fases G0/G1 y S, mientras que en el grupo DN DX los timocitos apoptóticos se distribuyen principalmente en la fase G0/G1. Estos resultados apoyan parcialmente las observaciones hechas por otros investigadores, en donde establecen que la dexametasona induce apoptosis en células quiescentes (Fearnhead y cols., 1994), principalmente en la fase G0/G1 (Provinciali y cols., 1998).

En ambos grupos tratados, no se encontró diferencia en la proporción de timocitos en cada fase respecto a sus grupos sin tratamiento. Lo que sugiere que la dexametasona afecta de forma similar a los timocitos de ratas bien nutridas y desnutridas.

Se ha propuesto que la apoptosis inducida por glucocorticoides requiere de la activación temprana de la CDK2, la cual es necesaria para desencadenar la 
permeabilidad mitocondrial, previo a la liberación del citocromo c y la activación de las caspasas -9 y -3; adicionalmente, la CDK2 está involucrada en la progresión de la fase G1 a S (Granes y cols., 2004).

En los cuatro grupos, la fase G2/M presentó la menor proporción de timocitos con actividad de caspasas, lo que puede relacionarse con características propias en esta etapa, ya que durante la fase de mitosis la cromatina se condensa, lo que impide la transcripción de genes, estableciendo una relación en la disminución de la expresión de genes que pueden estar involucrados en la apoptosis (Rieder, 2011).

\subsection{Apoptosis temprana en timocitos.}

La caspasa-9, es el resultado de la activación de la muerte celular "por abandono", lo que implica que muchas células están programadas para morir a menos que reciban estímulos de supervivencia, de tal forma que mueren si son abandonadas (Fraker y Lill-Elghanian, 2004). Esto puede relacionarse con la disminución de hormonas tímicas y su papel en la sobrevivencia de los timocitos CD4-CD8- y CD8+.

Los resultados muestran incremento de timocitos en apoptosis temprana, tanto por el análisis de caspasa-8 como por el de caspasa-9 en ratas DN respecto a ratas BN.

Al analizar la proporción de timocitos con caspasas -8 y -9 , en timocitos de ratas BN, se observaron porcentajes similares para ambas caspasas iniciadoras. Esto sugiere que la apoptosis de los timocitos de ratas BN puede ser iniciada tanto por la vía extrínseca como por la intrínseca. Lo que concuerda con el proceso de maduración de los timocitos, pues en etapas tempranas de CD4-CD8-, la expresión correcta y el 
reconocimiento del pre-TCR promueven la supervivencia y el metabolismo y fallas en este proceso impiden la supervivencia, induciendo apoptosis intrínseca. Por otra parte en CD4+CD8+ la selección negativa se da en aquellos timocitos que posean gran avidez por el complejo proteína-MHC propios, el cual es un proceso esencial para la tolerancia central (Carpenter y Bosselut, 2010). En la selección negativa se ha involucrado la expresión del factor AIRE (regulador autoinmune) por células epiteliales medulares (mTECs), estas células pueden exhibir características de "células presentadoras de antígenos", con habilidades para expresar variedad de antígenos tejido-específico y de expresar miembros de la superfamilia del factor de necrosis tumoral (Yamaguchi y cols., 2011) lo que sugiere su capacidad para inducir la apoptosis por vía extrínseca.

Al analizar la proporción de timocitos con caspasas -8 y -9 , en timocitos de ratas DN, se encontró una clara tendencia al incremento de timocitos con caspasa-9 en la fase temprana de muerte, sugiriendo que el incremento de apoptosis podría estar relacionado con la activación de la muerte "por abandono", posiblemente relacionado con: 1) falta de estímulos de supervivencia en el ambiente intratímico, 2) deficiencia en la respuesta a ellos por parte de los timocitos, o con ambos.

\subsection{Apoptosis temprana en las subpoblaciones de timocitos.}

Los resultados muestran incremento de la proporción de timocitos en apoptosis temprana en el grupo DN en cada subpoblación, mediante el análisis por caspasa-8 como por caspasa-9, respecto al grupo BN, lo que indica que ambas vías iniciadoras 
están involucradas en el incremento de la apoptosis en timocitos de ratas DN, debido a que ambas vías iniciadoras son críticas para el control durante el proceso de maduración/diferenciación de los timocitos, es probable que exista deficiencia en la expresión de características que promuevan su sobrevivencia, tal y como sucede en la deficiencia de la señal de sobrevivencia mediada por el pre-TCR en los timocitos CD4-CD8-. Se ha demostrado que los timocitos CD4-CD8- expresan diferentes tipos de receptores de muerte (Zhang y cols., 2005), algún defecto en la expresión del preTCR se puede relacionar al incremento de apoptosis intrínseca y extrínseca en esta subpoblación.

En ratas $\mathrm{BN}$ no se observó diferencia entre los timocitos con caspasa-8 y los positivos a caspasa-9, para cada subpoblación, lo que sugiere que en timocitos de ratas bien nutridas, los puntos de control en la muerte están dirigidos tanto por la activación de la vía intrínseca como por la extrínseca, dependiendo del estado de maduración de los timocitos (Carpenter y Bosselut, 2010). En desnutrición, contrariamente a lo observado en ratas BN, se observó incremento en la proporción de timocitos en apoptosis temprana mediante el análisis contra la caspasa-9, en comparación al análisis contra la caspasa-8, para las subpoblaciones: CD4-CD8-, CD4+CD8+ y CD8+ .

De acuerdo al proceso de maduración, los timocitos CD4-CD8- además de la señal del pre-TCR en la fase temprana de maduración, requieren de estímulos de sobrevivencia (p.ej. IL-7) y en ausencia de ellos mueren por abandono. 
Los timocitos CD4+CD8+ son seleccionados negativamente al expresar un TCR de muy alta afinidad, induciendo apoptosis vía extrínseca; algunos otros son seleccionados positivamente para promover su maduración y sobrevivencia, pero en ausencia de estos estímulos los timocitos mueren por apoptosis vía intrínseca (Zhang y cols., 2005).

Los resultados muestran que ambas vías están involucradas en el incremento de apoptosis en timocitos CD4-CD8-, CD4+CD8+ y CD8+; sin embargo una proporción mayor de ellos están muriendo por abandono. Posiblemente el incremento de la apoptosis tenga relación con defectos en la expresión de moléculas en los timocitos CD4-CD8- y CD4+CD8+, o deficiencias en la señal de sobrevivencia para los timocitos, como en el caso de las interleucinas y hormonas tímicas (Chandra, 1979), lo que podría influir negativamente en su sobrevivencia y diferenciación.

La subpoblación CD4+ mostró la proporción más alta de apoptosis temprana mediante el análisis de caspasa-8 y caspasa-9, sin embargo, en el análisis por caspasas inespecíficas (poli-caspasas) los timocitos CD4+ presentaron una de las proporciones más bajas en apoptosis tardía, respecto a las otras subpoblaciones. 


\section{CONCLUSIONES Y PERSPECTIVAS.}

De acuerdo con los resultados obtenidos en el presente trabajo se puede concluir que:

\# La desnutrición afecta negativamente el desarrollo del timo, favoreciendo el incremento de la apoptosis temprana y tardía en los timocitos.

\# La dexametasona posee un efecto negativo en el timo de forma independiente a la condición nutricional.

\# Los timocitos CD4-CD8- y CD8+ son las subpoblaciones más afectadas por la apoptosis, en nuestro modelo de desnutrición.

\# La desnutrición afecta la proporción de las subpoblaciones de timocitos, pero no la proporción de timocitos en las fases del ciclo celular.

\# En condiciones normales, la mayor proporción de timocitos apoptóticos se concentran en las fases G0/G1 y S, mientras que en desnutrición se observa solamente en G0/G1.

\# En la desnutrición se observó incremento de la proporción de timocitos positivos a caspasas -8 y -9 , por lo que ambas vías iniciadoras colaboran para el desencadenamiento de apoptosis; sin embargo, la proporción de timocitos positivos a caspasa-9 fue mayor que los positivos a caspasa-8, en CD4-CD8-, CD4+CD8+ y CD8+, lo que sugiere que la vía intrínseca juega un papel importante en el incremento de la apoptosis en dichas subpoblaciones.

En los grupos de ratas $\mathrm{BN}$ y $\mathrm{DN}$, la subpoblación CD4+ presentó los valores más altos de actividad de caspasas en la fase temprana de muerte, sin mostrar diferencia 
entre la proporción de timocitos analizados por caspasas -8 y -9 ; sin embargo, mediante el análisis de actividad de caspasas inespecíficas (poli-caspasas), estos timocitos no fueron los más afectados en BN, ni en DN, lo que deja en interrogante el comportamiento de los timocitos CD4+ ante la apoptosis.

Cabe señalar que se requieren de estudios posteriores que relacionen a la apoptosis en las diferentes fases del ciclo celular en cada subpoblación de timocitos, para poder determinar la existencia de la susceptibilidad a la apoptosis, su relación con la progresión del ciclo celular y las vías iniciadoras de la apoptosis.

Se requieren de estudios confirmativos sobre el papel de la vía intrínseca en el incremento de apoptosis en los timocitos CD4-CD8-, CD4+CD8+ y CD8+.

Finalmente, es necesario determinar las posibles causas involucradas en el aumento de los timocitos en apoptosis temprana identificados mediante el análisis de la caspasa-8 y su relación con posibles alteraciones en las células tímicas y el proceso de maduración en los timocitos en la desnutrición. 


\section{REFERENCIAS BIBLIOGRÁFICAS.}

\# Barone, K. S., O'Brien, P. C., y Stevenson, J. R. (1993). Characterization and mechanisms of thymic atrophy in protein-malnourished mice: role of corticosterone. Cell Immunol 148(1), 226-33.

\# Berki, T., Palinkas, L., Boldizsar, F., y Nemeth, P. (2002). Glucocorticoid (GC) sensitivity and GC receptor expression differ in thymocyte subpopulations. Int Immunol 14(5), 463-9.

\# Bianchini, R., Nocentini, G., Krausz, L. T., Fettucciari, K., Coaccioli, S., Ronchetti, S., y Riccardi, C. (2006). Modulation of pro- and antiapoptotic molecules in double-positive (CD4+CD8+) thymocytes following dexamethasone treatment. J Pharmacol Exp Ther 319(2), 887-97.

\# Boumpas, D. T., Chrousos, G. P., Wilder, R. L., Cupps, T. R., y Balow, J. E. (1993). Glucocorticoid therapy for immune-mediated diseases: basic and clinical correlates. Ann Intern Med 119(12), 1198-208.

\# Breuner, C. W., y Orchinik, M. (2002). Plasma binding proteins as mediators of corticosteroid action in vertebrates. J Endocrinol 175(1), 99-112.

\# Bronte, V., y Zanovello, P. (2005). Regulation of immune responses by L-arginine metabolism. Nat Rev Immunol 5(8), 641-54.

\# Brunner, T., y Mueller, C. (2003). Apoptosis in disease: about shortage and excess. Essays Biochem 39, 119-30.

\# Buttgereit, F., Brand, M. D., y Burmester, G. R. (1999). Equivalent doses and relative drug potencies for non-genomic glucocorticoid effects: a novel glucocorticoid hierarchy. Biochem Pharmacol 58(2), 363-8.

\# Carpenter, A. C., y Bosselut, R. (2010). Decision checkpoints in the thymus. Nat Immunol 11(8), 666-73.

\# Cohen, G. M. (1997). Caspases: the executioners of apoptosis. Biochem J 326 ( Pt 1), 1-16.

\# Cohen, J. (1992). Glucocorticoid-induced apoptosis in the thymus. Semin Immunol. $4(6), 363-9$.

\# Chandra, R. K. (1979). Serum thymic hormone activity in protein-energy malnutrition. Clin Exp Immunol 38(2), 228-30. 
\# Chandra, R. K. (2002). Nutrition and the immune system from birth to old age. Eur J Clin Nutr 56 Suppl 3, S73-6.

\# Chen, W. (2004). The late stage of T cell development within mouse thymus. Cell Mol Immunol 1(1), 3-11.

\# DeGregori, J., Leone, G., Miron, A., Jakoi, L., y Nevins, J. R. (1997). Distinct roles for E2F proteins in cell growth control and apoptosis. Proc Natl Acad Sci U S A 94(14), 7245-50.

\# Desoize, B., y Sen, S. (1992). [Apoptosis or programmed cell death: concepts, mechanisms and contribution in oncology]. Bull Cancer 79(5), 413-25.

\# Ekert, P. G., Silke, J., y Vaux, D. L. (1999). Caspase inhibitors. Cell Death Differ 6(11), 1081-6.

\# Fearnhead, H. O., Chwalinski, M., Snowden, R. T., Ormerod, M. G., y Cohen, G. M. (1994). Dexamethasone and etoposide induce apoptosis in rat thymocytes from different phases of the cell cycle. Biochem Pharmacol 48(6), 1073-9.

\# Feliu, S., y Slobodianik, H. (2002). Efectos de la desnutrición proteica y de su recuperación nutricional en el timo de rata. Rev Chil Nutr 29, 125-135.

\# Fraker, P. J., y Lill-Elghanian, D. A. (2004). The many roles of apoptosis in immunity as modified by aging and nutritional status. J Nutr Health Aging 8(1), 56-63.

\# Gómez, F. (1946). Desnutrición. Bol Med Hosp Infant Mex 3(4), 543-51.

\# Gómez, F., Aguilar, R., y Muñoz, J. (1947). La desnutrición infantil en México. Bol Med Hosp Infant Mex 4, 665-77.

\# Granes, F., Roig, M. B., Brady, H. J., y Gil-Gomez, G. (2004). Cdk2 activation acts upstream of the mitochondrion during glucocorticoid induced thymocyte apoptosis. Eur J Immunol 34(10), 2781-90.

\# Guchelaar, H. J., Vermes, A., Vermes, I., y Haanen, C. (1997). Apoptosis: molecular mechanisms and implications for cancer chemotherapy. Pharm World Sci 19(3), 11925.

\# Jambon, B., Zalles, L., Sevilla, R., Bustos, M., Cuellar, E., Chevallier, P., Dhenin, J., y Parent, G. (1988). Inmunocompetencia y función hormonal linfodiferenciativa del timo del niño desnutrido. Rev Chil Nutr 16, 147-151.

\# Joao, B., Leonardo, J., y John, E. (1968). Malnutrition and the common communicable diseases of childhood in rural Guatemala. Am J Pub. Health. Nat. Health 58, 505-16. 
\# Kerr, J. F., Winterford, C. M., y Harmon, B. V. (1994). Apoptosis. Its significance in cancer and cancer therapy. Cancer 73(8), 2013-26.

\# Lecoeur, H., Ledru, E., Prevost, M. C., y Gougeon, M. L. (1997). Strategies for phenotyping apoptotic peripheral human lymphocytes comparing ISNT, annexin-V and 7-AAD cytofluorometric staining methods. J Immunol Methods 209(2), 111-23.

\# Lyra, J. S., Madi, K., Maeda, C. T., y Savino, W. (1993). Thymic extracellular matrix in human malnutrition. J Pathol 171(3), 231-6.

\# Manary, M. J., Muglia, L. J., Vogt, S. K., y Yarasheski, K. E. (2006). Cortisol and its action on the glucocorticoid receptor in malnutrition and acute infection. Metabolism 55(4), 550-4.

\# McColl, K. S., He, H., Zhong, H., Whitacre, C. M., Berger, N. A., y Distelhorst, C. W. (1998). Apoptosis induction by the glucocorticoid hormone dexamethasone and the calcium-ATPase inhibitor thapsigargin involves Bc1-2 regulated caspase activation. Mol Cell Endocrinol 139(1-2), 229-38.

\# Mostl, E., y Palme, R. (2002). Hormones as indicators of stress. Domest Anim Endocrinol 23(1-2), 67-74.

\# Mukherjee, K. L. (1967). Classification of protein-calorie undernutrition in children. Arch Dis Child 42(226), 647-51.

\# Nahle, Z., Polakoff, J., Davuluri, R. V., McCurrach, M. E., Jacobson, M. D., Narita, M., Zhang, M. Q., Lazebnik, Y., Bar-Sagi, D., y Lowe, S. W. (2002). Direct coupling of the cell cycle and cell death machinery by E2F. Nat Cell Biol 4(11), 859-64.

\# Olaiz-Fernández, G., Rivera-Dommarco, J., Shamah-Levy, T., Rojas, R., VillalpandoHernández, S., Hernández-Avila, M., y Sepúlveda-Amor, J. (2006). Encuesta Nacional de Salud y Nutrición. Instituto Nacional de Salud Pública. 2006.

\# Ortiz, R., Cortés, E., Pérez, L., González, C., y Betancourt, M. (1996). Assessment of an experimental method to induce malnutrition by food competition during lactation. Med Sci Res 24, 843-846.

\# Ortiz, R., Cortés, L., Cortés, E., y Medina, H. (2009). Malnutrition alters the rates of apoptosis in splenocytes and thymocyte subpopulations of rats. Clin Exp Immunol 155(1), 96-106. 
\# Ortiz, R., Cortés, L., González-Marquez, H., Gómez, J. L., González, C., y Cortés, E. (2001). Flow cytometric analysis of spontaneous and dexamethasone-induced apoptosis in thymocytes from severely malnourished rats. Br J Nutr 86(5), 545-8.

\# Pallaro, A. (1997). Efecto de la calidad proteica sobre el timo de rata en período de crecimiento activo. Tesis doctoral Facultad de Farmacia y Bioquímica(Universidad de Buenos Aires).

\# Pellicciari, C., Bottone, M. G., Schaack, V., Barni, S., y Manfredi, A. A. (1996). Spontaneous apoptosis of thymocytes is uncoupled with progression through the cell cycle. Exp Cell Res 229(2), 370-7.

\# Pérez-Robles, R., Nina, R., Tejeda, S., Acosta, C., Acosta, J., y Vitoria, M. (1994). Características de la desnutrición en niños menores de seis años residentes en zona rural fronteriza. Rev Med Dom 55, 24-26.

\# Prentice, A. M. (1999). The thymus: a barometer of malnutrition. Br J Nutr 81(5), 345-7.

\# Provinciali, M., Di Stefano, G., y Stronati, S. (1998). Flow cytometric analysis of CD3/TCR complex, zinc, and glucocorticoid-mediated regulation of apoptosis and cell cycle distribution in thymocytes from old mice. Cytometry 32(1), 1-8.

\# Prudhon, C. (2002). "Evaluación y tratamiento de la desnutrición en situaciones de emergencia: manual del tratamiento terapéutico de la desnutrición y planificación de un programa nutricional." Icaria.

\# Purtilo, D. T., y Connor, D. H. (1975). Fatal infections in protein-calorie malnourished children with thymolymphatic atrophy. Arch Dis Child 50(2), 149-52.

\# Rieder, C. L. (2011). Mitosis in vertebrates: the G2/M and M/A transitions and their associated checkpoints. Chromosome Res 19(3), 291-306.

\# Rotonda, J., Nicholson, D. W., Fazil, K. M., Gallant, M., Gareau, Y., Labelle, M., Peterson, E. P., Rasper, D. M., Ruel, R., Vaillancourt, J. P., Thornberry, N. A., y Becker, J. W. (1996). The three-dimensional structure of apopain/CPP32, a key mediator of apoptosis. Nat Struct Biol 3(7), 619-25.

\# Savino, W. (2002). The thymus gland is a target in malnutrition. Eur J Clin Nutr 56 Suppl 3, S46-9.

\# Scrimshaw, N. S., Taylor, C. E., y Gordon, J. E. (1968). Interactions of nutrition and infection. Monogr Ser World Health Organ 57, 3-329. 
\# Schaaf, M. J., y Cidlowski, J. A. (2002). Molecular mechanisms of glucocorticoid action and resistance. J Steroid Biochem Mol Biol 83(1-5), 37-48.

\# Schaible, U. E., y Kaufmann, S. H. (2007). Malnutrition and infection: complex mechanisms and global impacts. PLoS Med 4(5), e115.

\# Schmid, I., Krall, W. J., Uittenbogaart, C. H., Braun, J., y Giorgi, J. V. (1992). Dead cell discrimination with 7-amino-actinomycin $\mathrm{D}$ in combination with dual color immunofluorescence in single laser flow cytometry. Cytometry 13(2), 204-8.

\# Seckl, J. R. (1997). 11beta-Hydroxysteroid dehydrogenase in the brain: a novel regulator of glucocorticoid action? Front Neuroendocrinol 18(1), 49-99.

\# Sionov, R. V., Cohen, O., Kfir, S., Zilberman, Y., y Yefenof, E. (2006a). Role of mitochondrial glucocorticoid receptor in glucocorticoid-induced apoptosis. J Exp Med 203(1), 189-201.

\# Sionov, R. V., Kfir, S., Zafrir, E., Cohen, O., Zilberman, Y., y Yefenof, E. (2006b). Glucocorticoid-induced apoptosis revisited: a novel role for glucocorticoid receptor translocation to the mitochondria. Cell Cycle 5(10), 1017-26.

\# Strasser, A., Jost, P. J., y Nagata, S. (2009). The many roles of FAS receptor signaling in the immune system. Immunity 30(2), 180-92.

\# Tamayo, F. G. (1997). "Fundamentos de Inmunobiologĺa." UNAM.

\# Thornberry, N. A., y Molineaux, S. M. (1995). Interleukin-1 beta converting enzyme: a novel cysteine protease required for IL-1 beta production and implicated in programmed cell death. Protein Sci 4(1), 3-12.

\# Thornberry, N. A., Rano, T. A., Peterson, E. P., Rasper, D. M., Timkey, T., GarciaCalvo, M., Houtzager, V. M., Nordstrom, P. A., Roy, S., Vaillancourt, J. P., Chapman, K. T., y Nicholson, D. W. (1997). A combinatorial approach defines specificities of members of the caspase family and granzyme B. Functional relationships established for key mediators of apoptosis. J Biol Chem 272(29), 17907-11.

\# Viret, C., y Janeway, C. A., Jr. (1999). MHC and T cell development. Rev Immunogenet 1(1), 91-104.

\# Viret, C., Sant'Angelo, D. B., He, X., Ramaswamy, H., y Janeway, C. A., Jr. (2001). A role for accessibility to self-peptide-self-MHC complexes in intrathymic negative selection. J Immunol 166(7), 4429-37. 
\# Wang, D., Muller, N., McPherson, K. G., y Reichardt, H. M. (2006). Glucocorticoids engage different signal transduction pathways to induce apoptosis in thymocytes and mature T cells. J Immunol 176(3), 1695-702.

\# Waterlow, J. C. (1972). Classification and definition of protein-calorie malnutrition. $\mathrm{Br}$ Med J 3(5826), 566-9.

\# Xu, G., y Shi, Y. (2007). Apoptosis signaling pathways and lymphocyte homeostasis. Cell Res 17(9), 759-71.

\# Xue, L., Nolla, H., Suzuki, A., Mak, T. W., y Winoto, A. (2008). Normal development is an integral part of tumorigenesis in T cell-specific PTEN-deficient mice. Proc Natl Acad Sci U S A 105(6), 2022-7.

\# Xue, L., Sun, Y., Chiang, L., He, B., Kang, C., Nolla, H., y Winoto, A. (2010). Coupling of the cell cycle and apoptotic machineries in developing T cells. J Biol Chem 285(10), 7556-65.

\# Yamaguchi, Y., Takayanagi, A., Chen, J., Sakai, K., Kudoh, J., y Shimizu, N. (2011). Mouse thymic epithelial cell lines expressing "Aire" and peripheral tissue-specific antigens reproduce in vitro negative selection of T cells. Exp Cell Res 317(14), 201930.

\# Zelenin, A. V., Poletaev, A. I., Stepanova, N. G., Barsky, V. E., Kolesnikov, V. A., Nikitin, S. M., Zhuze, A. L., y Gnutchev, N. V. (1984). 7-Amino-actinomycin D as a specific fluorophore for DNA content analysis by laser flow cytometry. Cytometry 5(4), 348-54.

\# Zhang, N., Hartig, H., Dzhagalov, I., Draper, D., y He, Y. W. (2005). The role of apoptosis in the development and function of T lymphocytes. Cell Res 15(10), 749-69.

\# Zhu, J. W., DeRyckere, D., Li, F. X., Wan, Y. Y., y DeGregori, J. (1999). A role for E2F1 in the induction of ARF, p53, and apoptosis during thymic negative selection. Cell Growth Differ 10(12), 829-38. 